\title{
Stereoselective Synthesis of New Chiral $N$-Tertiary Tetrasubstituted \\ $\beta$-Enamino Ester Piperidines through an Ammonia-Catalyzed Process
}

Sandrine Calvet-Vitale, Corinne Vanucci-Bacqué,* Marie-Claude Fargeau-Bellassoued and Gérard Lhommet*

Université P. et M. Curie, Institut de Chimie Moléculaire FR 2769, Laboratoire de Chimie Organique, UMR 7611, Equipe de Chimie des Hétérocycles, 4 Place Jussieu, 75252 Paris Cedex 05, France

vanucci@ccr.jussieu.fr; 1 hommet@ccr.jussieu.fr

\section{SUPPORTING INFORMATION}

\section{Table of Contents}

S2 General information

S2 Isomerization of compound (E)-5

S2 Preparation and characterization data of compound 7a

S3 Preparation of 2 a from 5

S5-S30 $\quad{ }^{1} \mathrm{H}$ and ${ }^{13} \mathrm{C}$ NMR spectra of compounds 11a-d, 6a-d, 2a-d and 7a. 


\section{General information:}

Unless otherwise specified, materials were purchased from commercial suppliers and used without further purification. THF was distilled from sodium/ benzophenone ketyl immediately prior to use. $\mathrm{CH}_{2} \mathrm{Cl}_{2}$ was distilled from calcium hydride. All reactions were carried out under argon. ${ }^{1} \mathrm{H}$ NMR spectra were recorded at $250 \mathrm{MHz}$ and ${ }^{13} \mathrm{C} \mathrm{NMR}$ at $62.5 \mathrm{MHz}$. Chemical shifts $(\delta)$ were expressed in ppm relative to TMS at $\delta=0$ for ${ }^{1} \mathrm{H}$ and to $\mathrm{CDCl}_{3}$ at $\delta=77.1$ for ${ }^{13} \mathrm{C}$ and coupling constants $(J)$ in Hertz.

\section{Isomerization of [1-(1(S)-phenylethyl)-piperidin-2-ylidene]acetic acid methyl ester ((E)-}

5). To a solution of compound $(E)-5(89 \mathrm{mg}, 3.42 \mathrm{mmol})$ in dry $\mathrm{MeOH}(10 \mathrm{~mL})$ was added $\mathrm{AcCl}(0.25 \mathrm{~mL}, 3.5 \mathrm{mmol})$. After stirring for $15 \mathrm{~min}$, the reaction mixture was concentrated in vacuo and dissolved in a $7 \mathrm{~N}$ methanolic solution of ammonia $(10 \mathrm{~mL})$ under argon. After 15 min stirring at room temperature, the solution was concentrated in vacuo and the solid residue dissolved in anhydrous THF $(10 \mathrm{~mL})$ under argon. This solution was canulated over a suspension of $\mathrm{NaH}(128 \mathrm{mg}, 5.13 \mathrm{mmol})$ in THF $(10 \mathrm{~mL})$. After stirring for $20 \mathrm{~min}$., the reaction mixture was filtered and the solid residue washed with $\mathrm{CH}_{2} \mathrm{Cl}_{2}$. The combined organic layer was concentrated in vacuo to give $90 \mathrm{mg}$ of a 1:1 mixture of (E)-5 and (Z)-5. Characteristic signals for (Z)-5 (from a mixture): ${ }^{1} \mathrm{H}$ NMR $\left(\mathrm{CDCl}_{3}\right) \delta 1.33(\mathrm{~d}, J=6.5 \mathrm{~Hz}, 3 \mathrm{H})$, $2.07(\mathrm{t}, J=7.25 \mathrm{~Hz}, 2 \mathrm{H}), 2.35-2.55(\mathrm{~m}, 2 \mathrm{H}), 3.59(\mathrm{~s}, 3 \mathrm{H}), 3.72(\mathrm{q}, J=6.5 \mathrm{~Hz}, 1 \mathrm{H}), 4.49(\mathrm{~s}$, $1 \mathrm{H}) ;{ }^{13} \mathrm{C} \mathrm{NMR}\left(\mathrm{CDCl}_{3}\right) \delta 24.3,25.6,29.5,30.2,36.0,47.2,58.3,82.7,126.4,127.3,128.3$, $145.6,163.8,170.6$.

\section{2-[1-(1-(S)-Phenylethyl)-1,4,5,6-tetrahydro-pyridin-2-yl]-propionic acid methyl ester}

(7a). A solution of 5 (530mg, $2 \mathrm{mmol})$ in methyl iodide $(10 \mathrm{~mL})$ was refluxed for $48 \mathrm{~h}$. The 
reaction mixture was concentrated in vacuo to give iminium ion Ia as a solid which was washed with $\mathrm{Et}_{2} \mathrm{O}(3 \times 20 \mathrm{~mL})$ and identified as a 70:30 mixture of isomers by NMR.

Treatment with $\mathrm{K}_{2} \mathrm{CO}_{3}$ : saturated aqueous solution of $\mathrm{K}_{2} \mathrm{CO}_{3}(15 \mathrm{~mL})$ was added to iminium Ia and the aqueous layer was extracted with $\mathrm{CHCl}_{3}(4 \times 10 \mathrm{~mL})$. The combined organic layer was washed with brine $(10 \mathrm{~mL})$, dried over $\mathrm{Na}_{2} \mathrm{SO}_{4}$ and concentrated in vacuo to give a 75:25 mixture of compound 7a (70:30 mixture of diastereoisomers) and $\mathbf{6 a}$ according to NMR (470 mg overall). This mixture was not further purified due to the instability of 7a.

Treatment with NaH: a suspension of intermediate iminium ion Ia in THF (5 mL) was transferred via canula on a suspension of $\mathrm{NaH}(120 \mathrm{mg}, 3 \mathrm{mmol})$ in THF $(6 \mathrm{~mL})$. After $5 \mathrm{~min}$ stirring, the mixture was filtrated and concentrated in vacuo to give crude compounds $7 \mathbf{a}$ and 6a (530 mg overall) as an oil.

Treatment with $\mathrm{NEt}_{3}$ : to solution of iminium ion $\mathbf{I a}$ in $\mathrm{MeOH}$ was added $\mathrm{NEt}_{3}(3 \mathrm{mmol})$. The reaction mixture was concentrated in vacuo and $\mathrm{Et}_{2} \mathrm{O}$ was added. After filtration, the solvent was removed to give crude compound 7a and $6 \mathbf{a}$ (500 mg overall).

From a mixture of the two isomers along with 6a: ${ }^{1} \mathrm{H}$ NMR $\left(\mathrm{CDCl}_{3}\right) \delta 1.25-1.56(\mathrm{~m}, 8 \mathrm{H})$, 1.98-2.05 $(\mathrm{m}, 2 \mathrm{H}), 2.68-2.83(\mathrm{~m}, 2 \mathrm{H}), 3.38-3.51(\mathrm{~m}, 1 \mathrm{H}), 3.69(\mathrm{~s}, 3 \mathrm{H}), 4.59$ and $4.65(2 \mathrm{t}, \mathrm{J}=$ $4 \mathrm{~Hz}, 1 \mathrm{H}), 4.68-4.76(\mathrm{~m}, 1 \mathrm{H}), 7.22-7.38(\mathrm{~m}, 5 \mathrm{H}) ;{ }^{13} \mathrm{C} \mathrm{NMR}\left(\mathrm{CDCl}_{3}\right) \delta 15.8,16.2,16.6$ and 17.3, 21.8 and 22.0, 22.9 and $23.7,42.3$ and $42.5,43.1$ and $43.4,51.8,54.2$ and 54.3, 99.4 and $100.2,126.4,126.8,127.1,127.2,128.0,128.3,142.8,143.0$ and $143.4,175.2$ and 175.4.

\section{Preparation of compound 2a from 5.}

A solution of $5(1 \mathrm{~g}, 3.86 \mathrm{mmol})$ in MeI $(10 \mathrm{~mL})$ was refluxed for $48 \mathrm{~h}$. The reaction mixture was concentrated in vacuo and the residue was washed with $\mathrm{Et}_{2} \mathrm{O}(3 \times 20 \mathrm{~mL})$ to afford intermediate iminium Ia. The latter was dissolved in a $7 \mathrm{~N}$ methanolic solution of ammonia $(10 \mathrm{~mL})$ under argon. After $15 \mathrm{~min}$ stirring at room temperature, the solution was 
concentrated in vacuo and the solid residue dissolved in anhydrous THF (10 mL) under argon. This solution was canulated over a suspension of $\mathrm{NaH}(232 \mathrm{mg}, 5.8 \mathrm{mmol})$ in THF $(10 \mathrm{~mL})$. After stirring for 20 min., the reaction mixture was filtered and the solid residue washed with THF. The combined organic layer was concentrated in vacuo and the residue was purified by bulb-to-bulb distillation $\left(200^{\circ} \mathrm{C}, 0.1 \mathrm{~mm} \mathrm{Hg}\right)$ to give the expected product $2 \mathbf{a}$ as colorless oil (937 mg) in 89\% yield. 


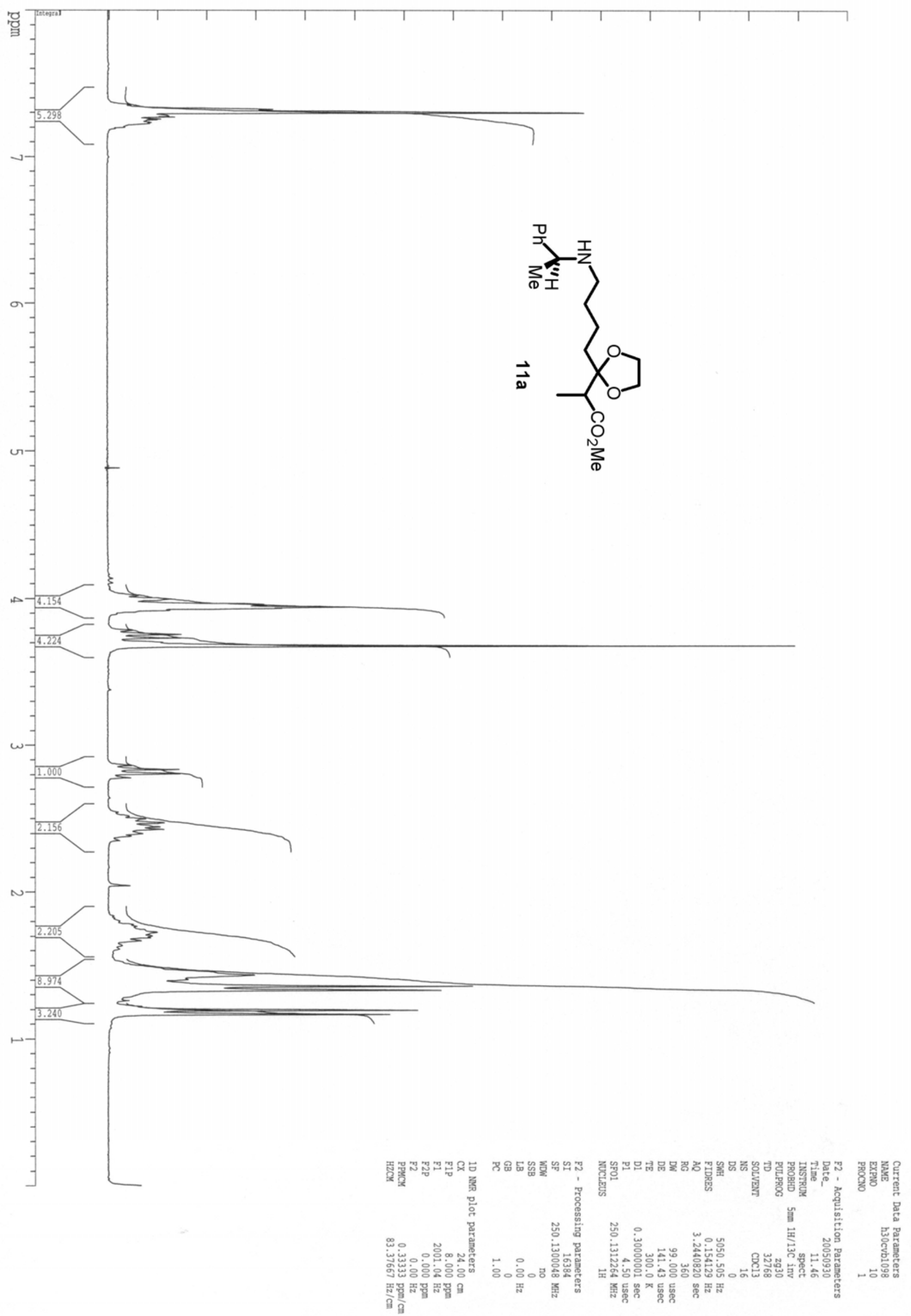




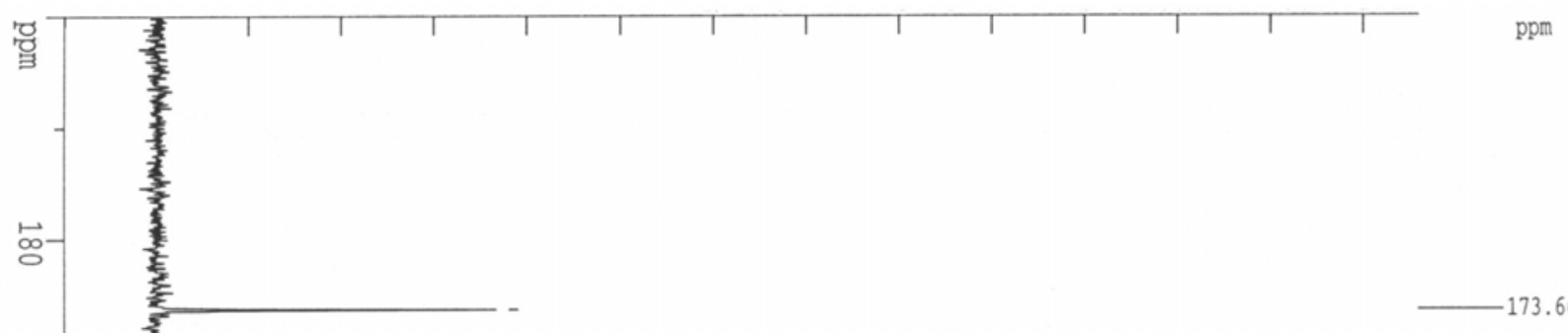

145.74

客

능

홍-

홍

s-

- 集$$
\text { ond }
$$

ㅇ-
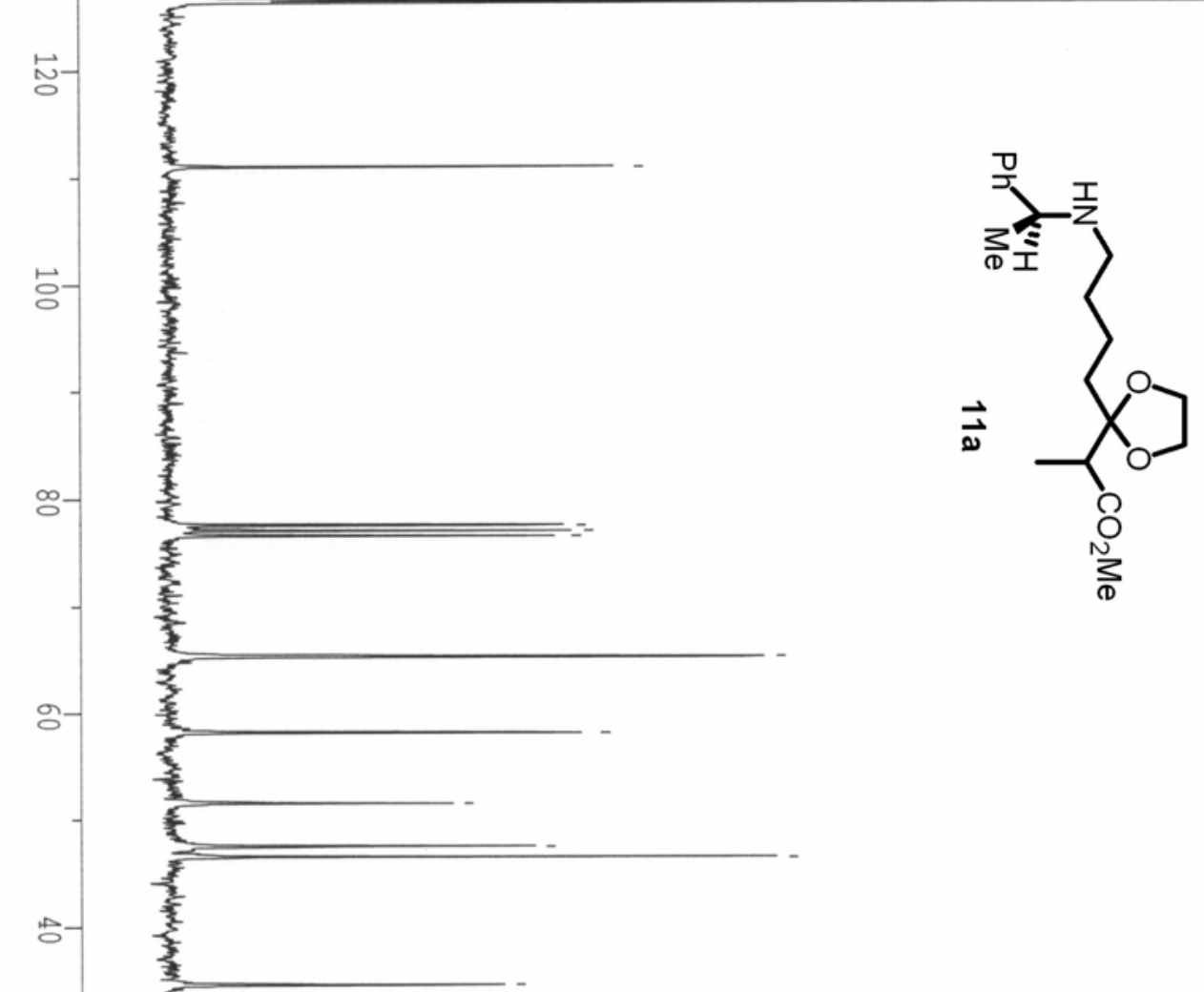

$-111.04$

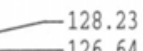

126.38 


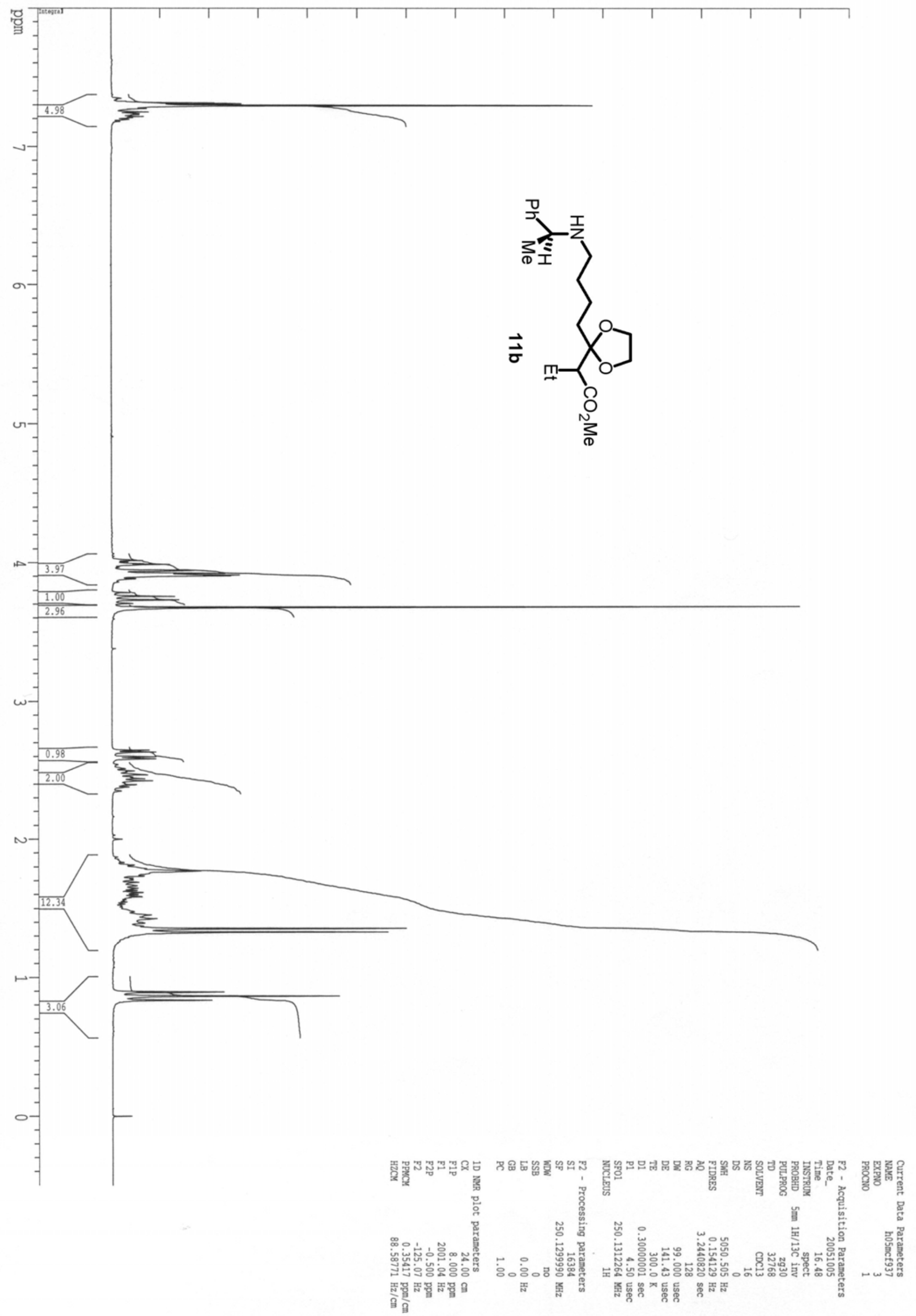



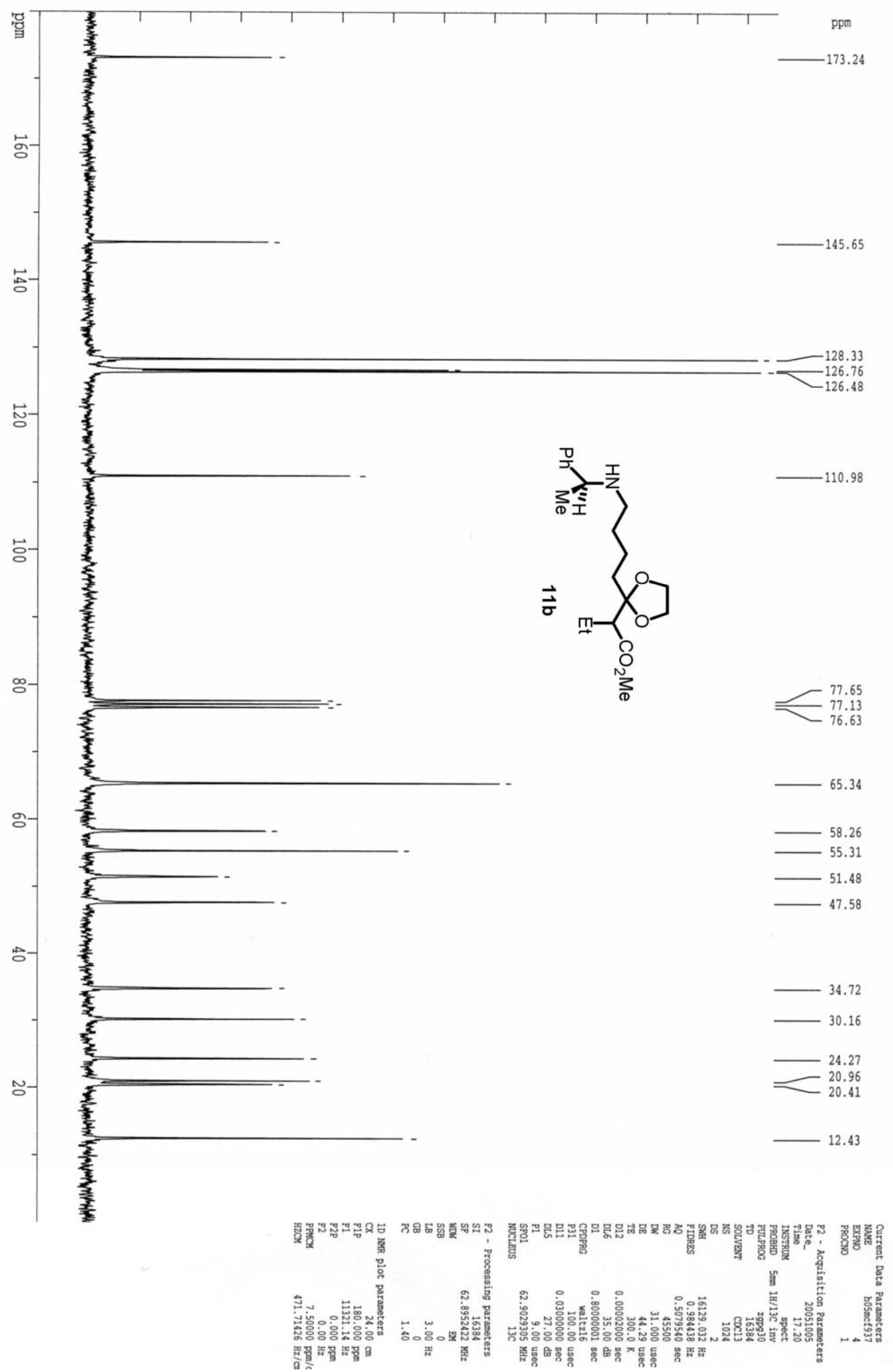


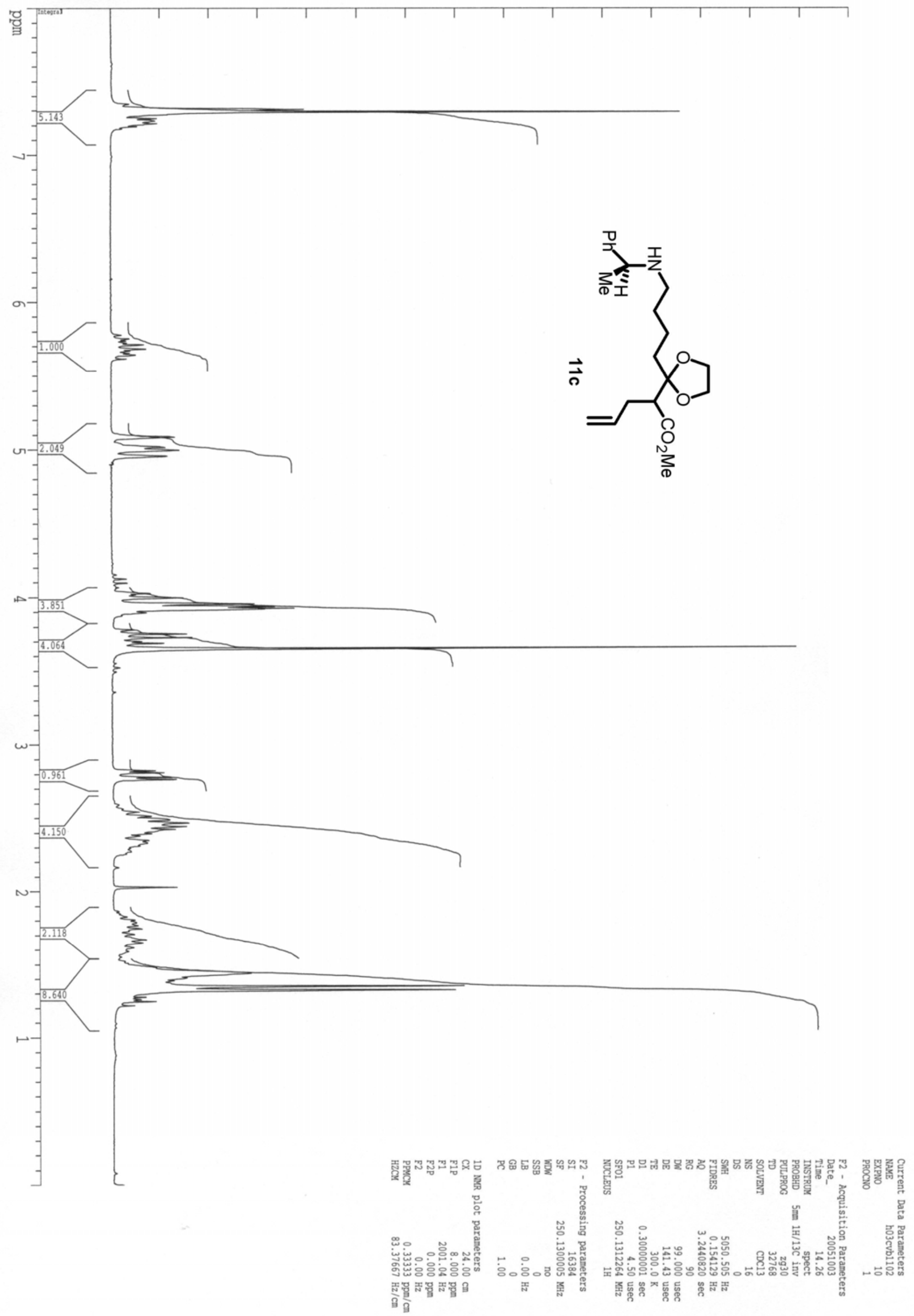



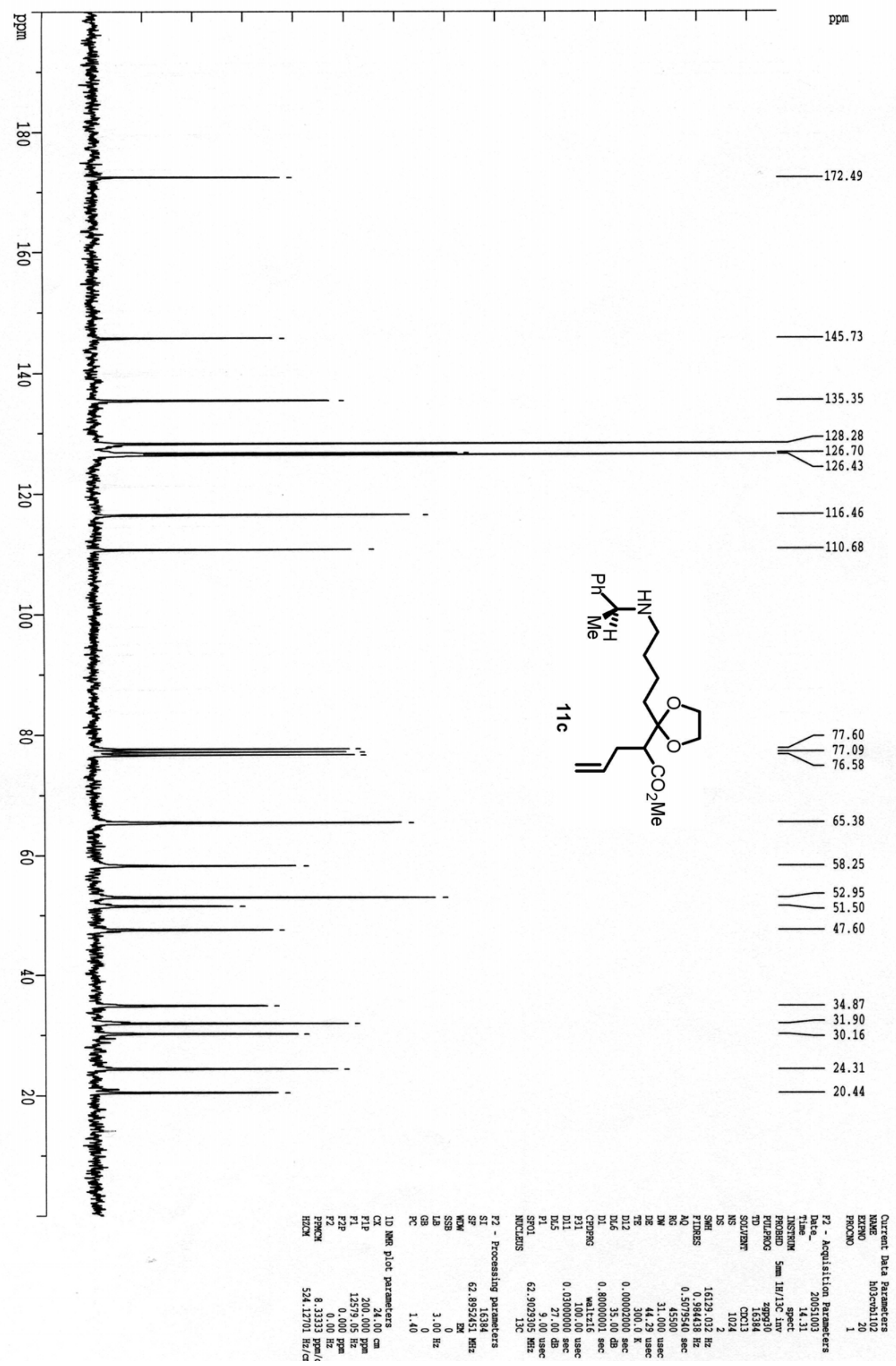


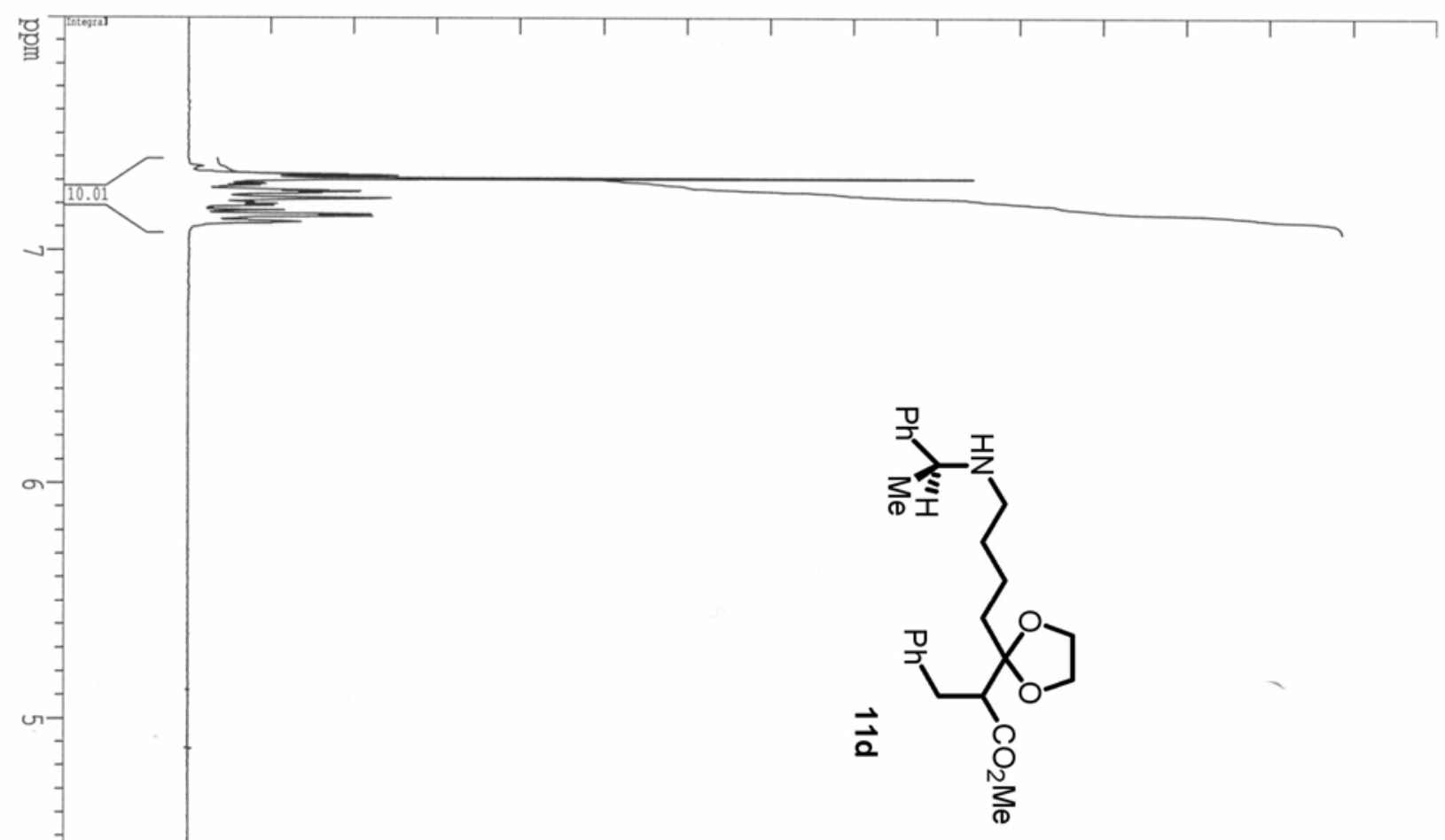



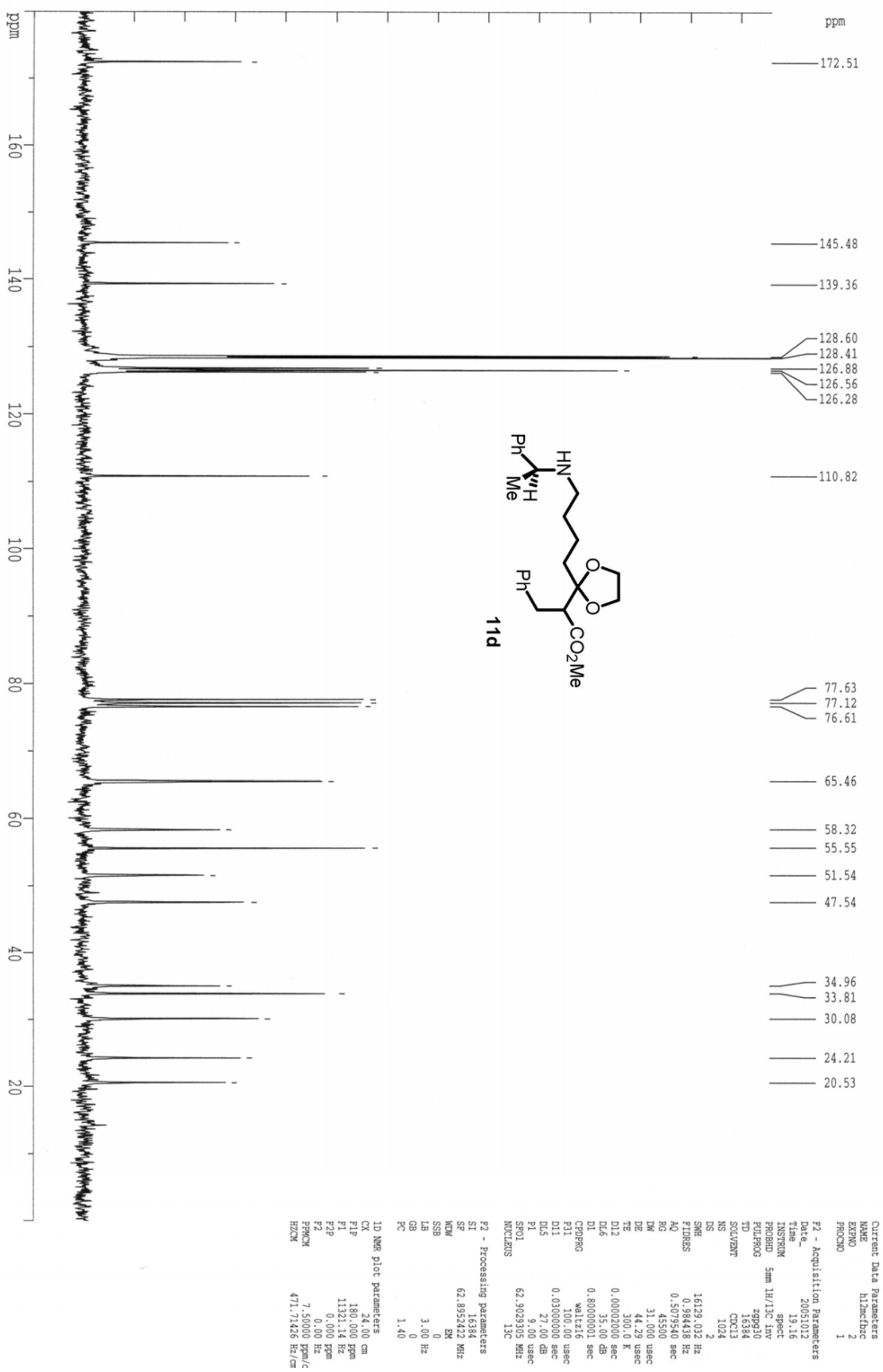


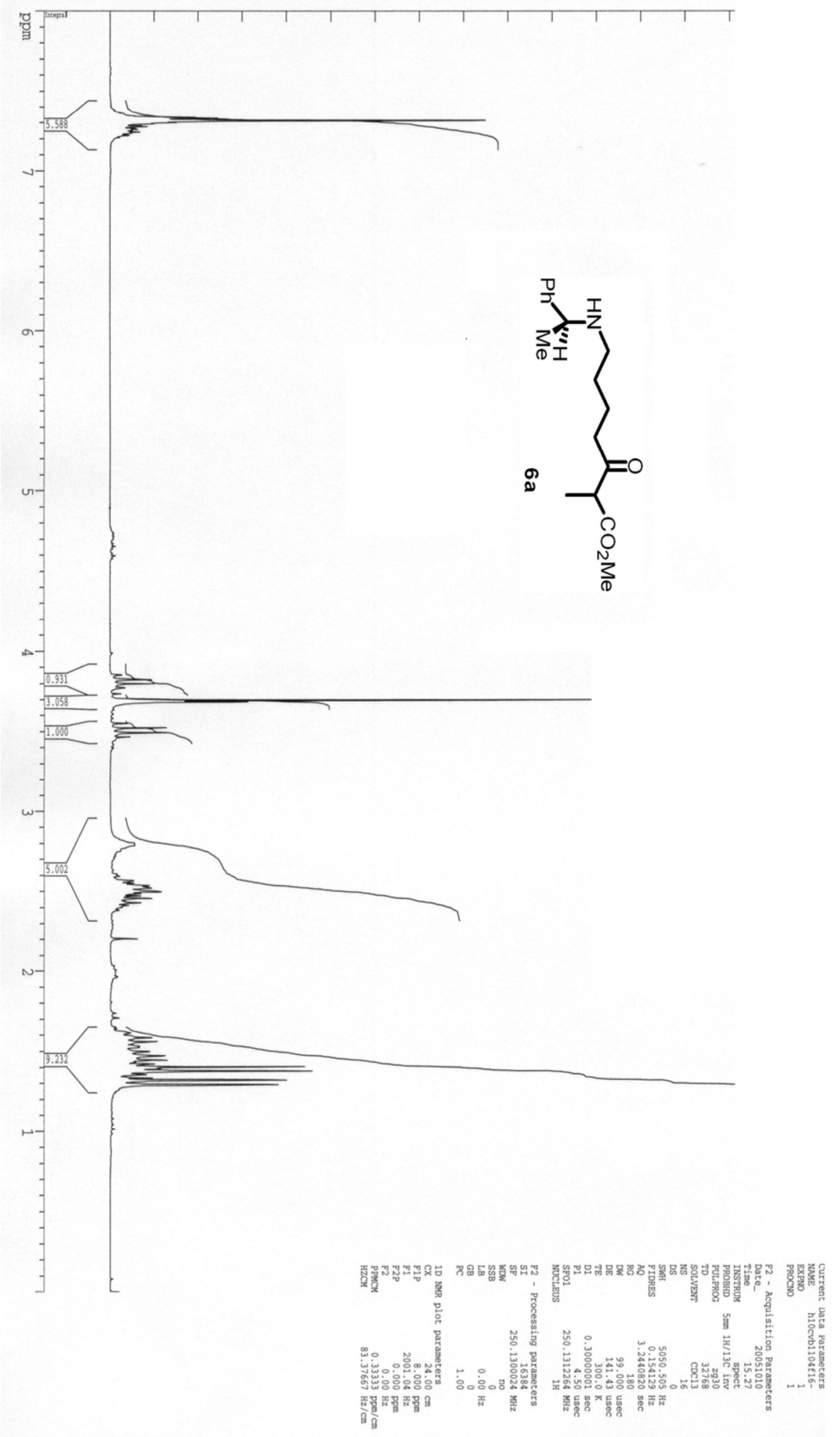




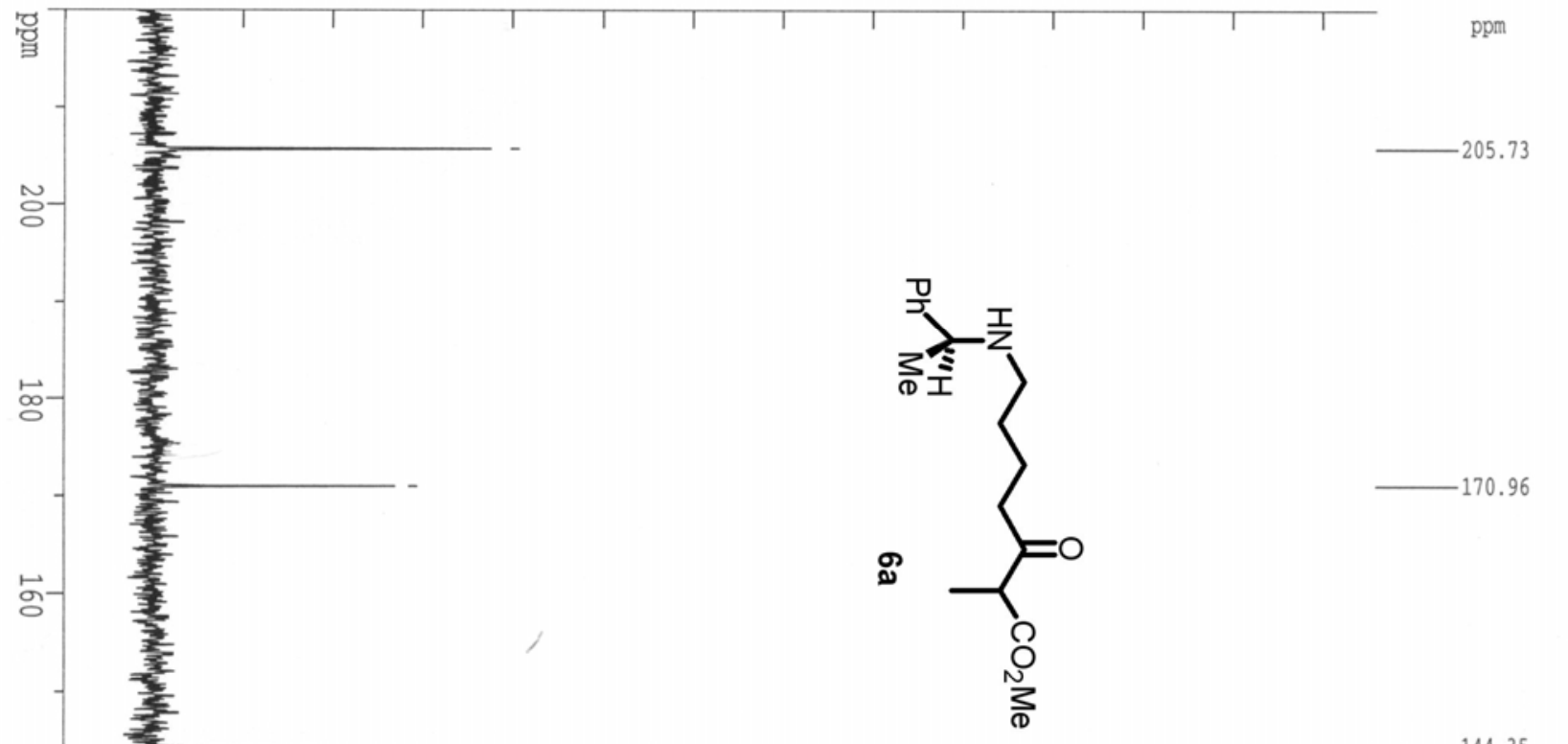

เ

흥

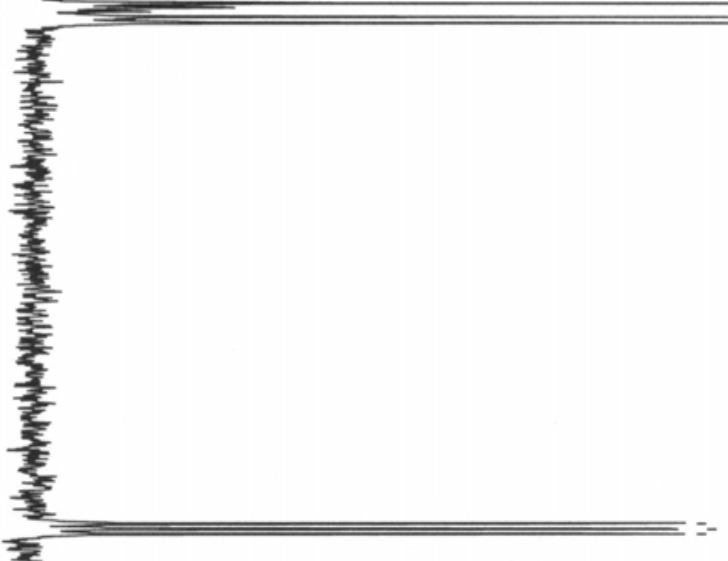

128.51

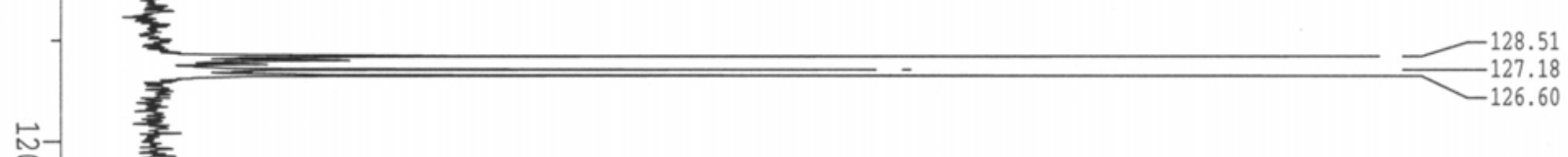

\&

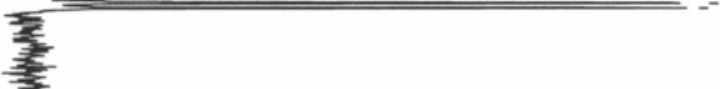

77.62

77.11

76.60

g

章

章

58.52

-52.48
$-\quad 52.27$

52.27

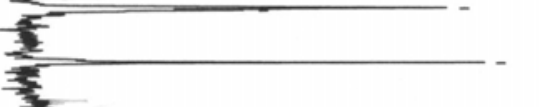

47.14

용

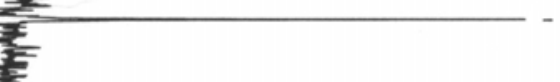

41.00

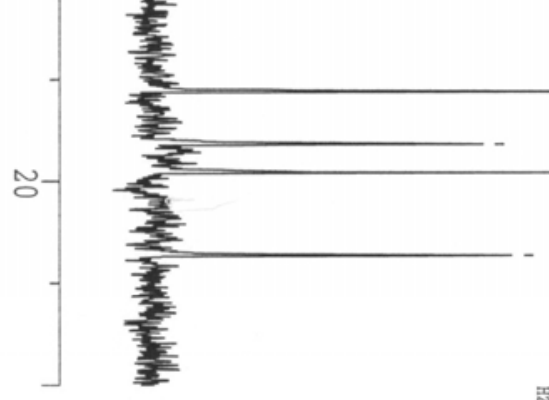

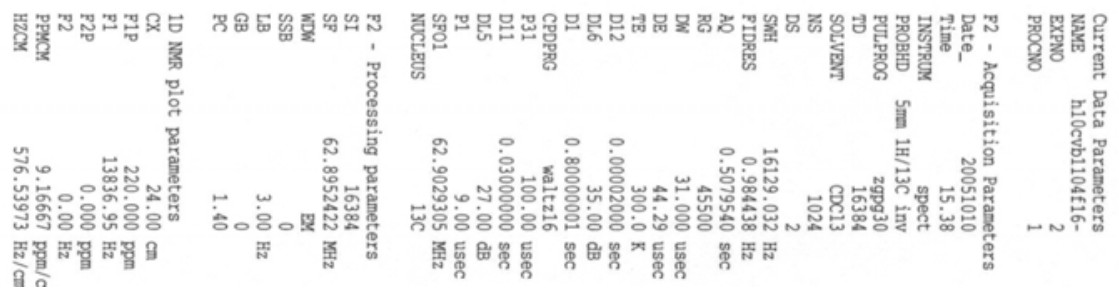




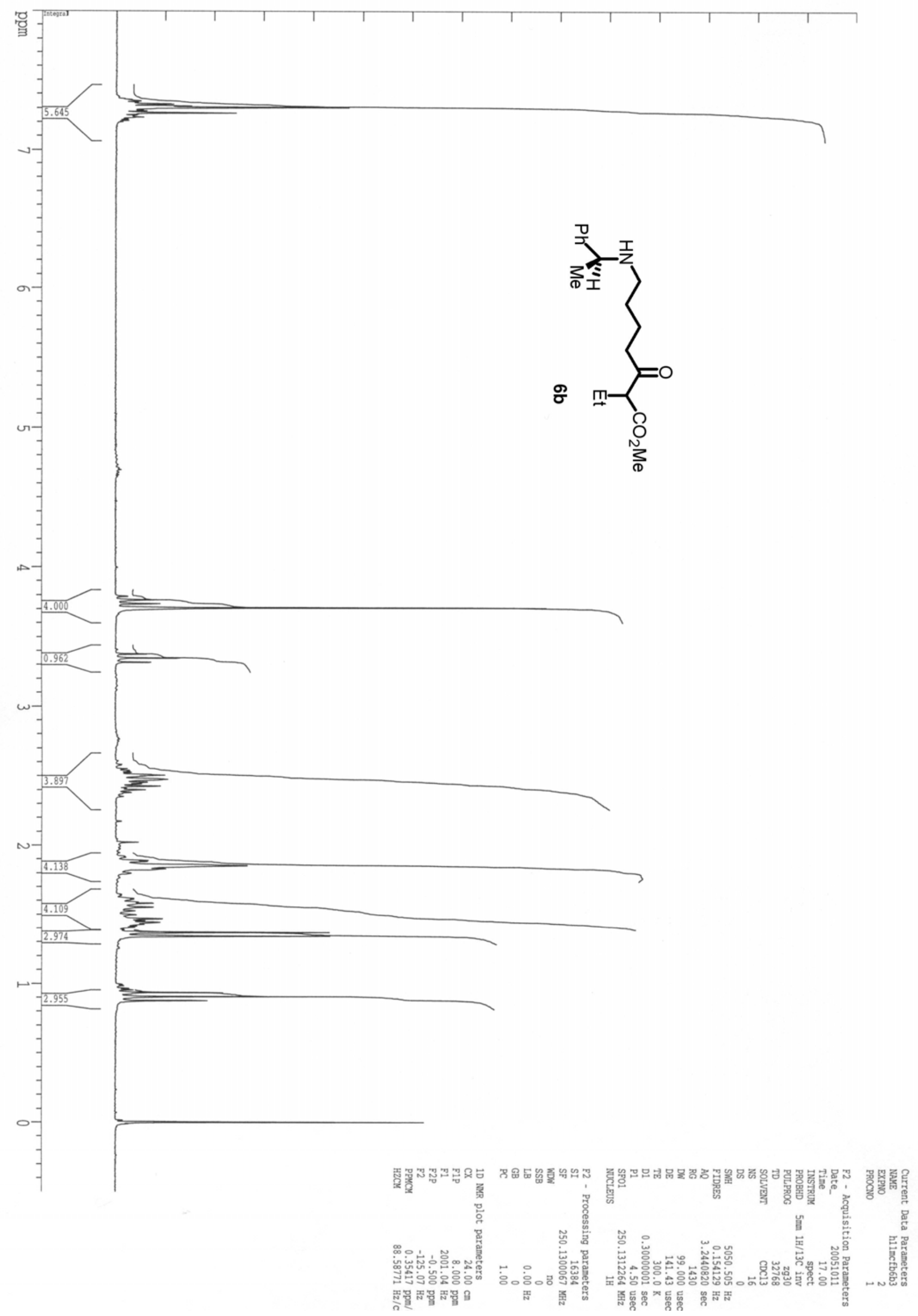




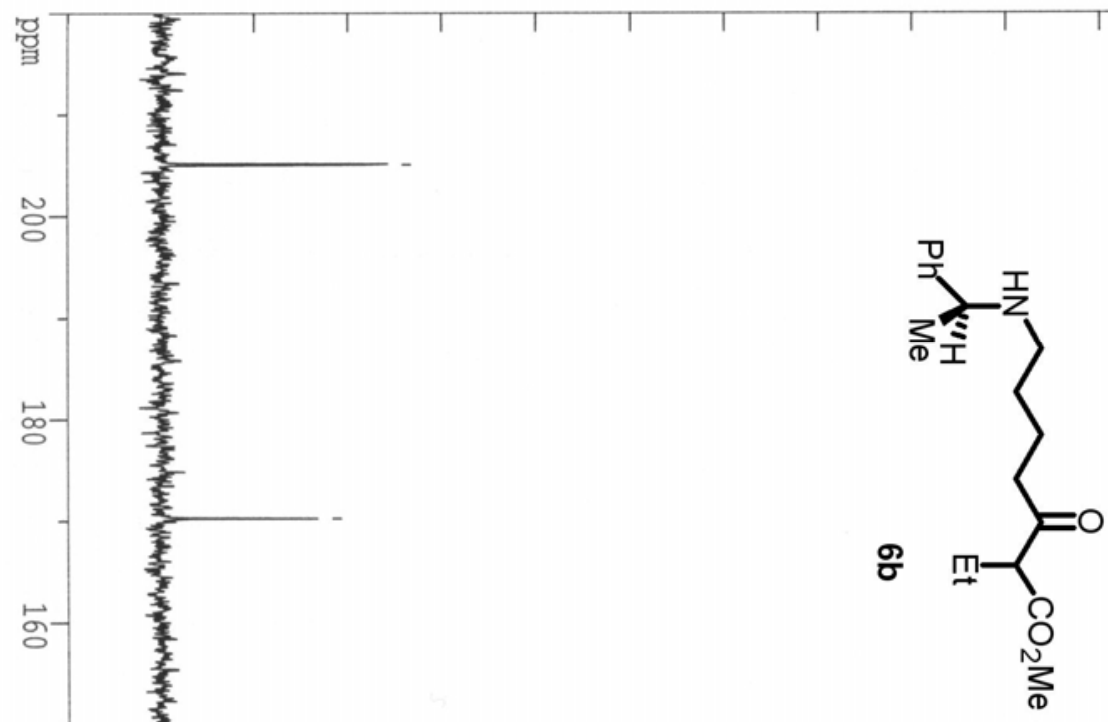

芯

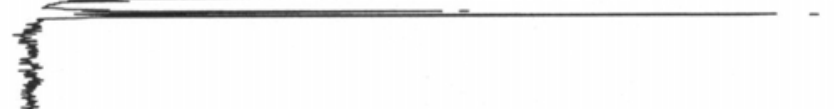

\section{응-}

\&-
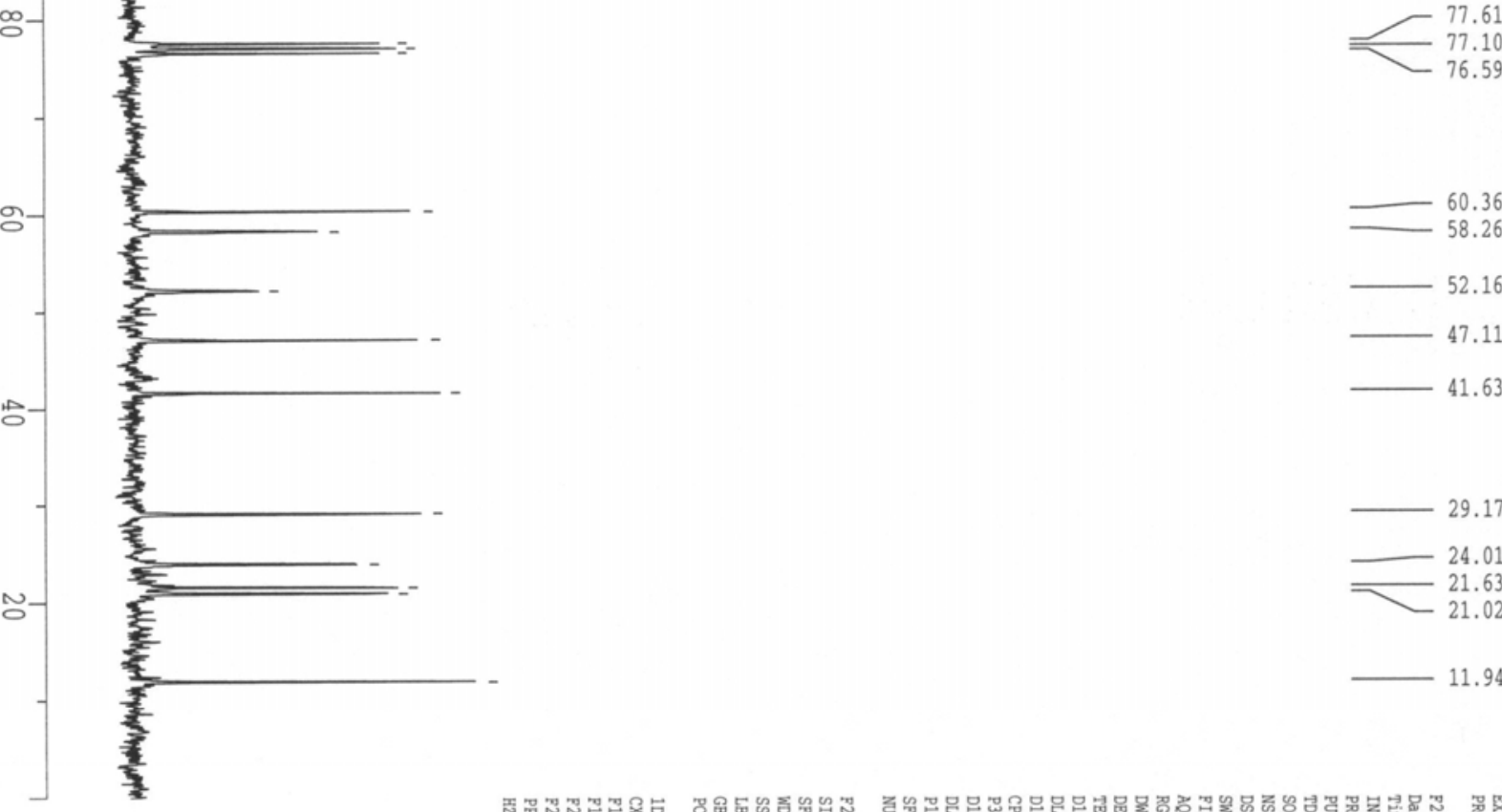


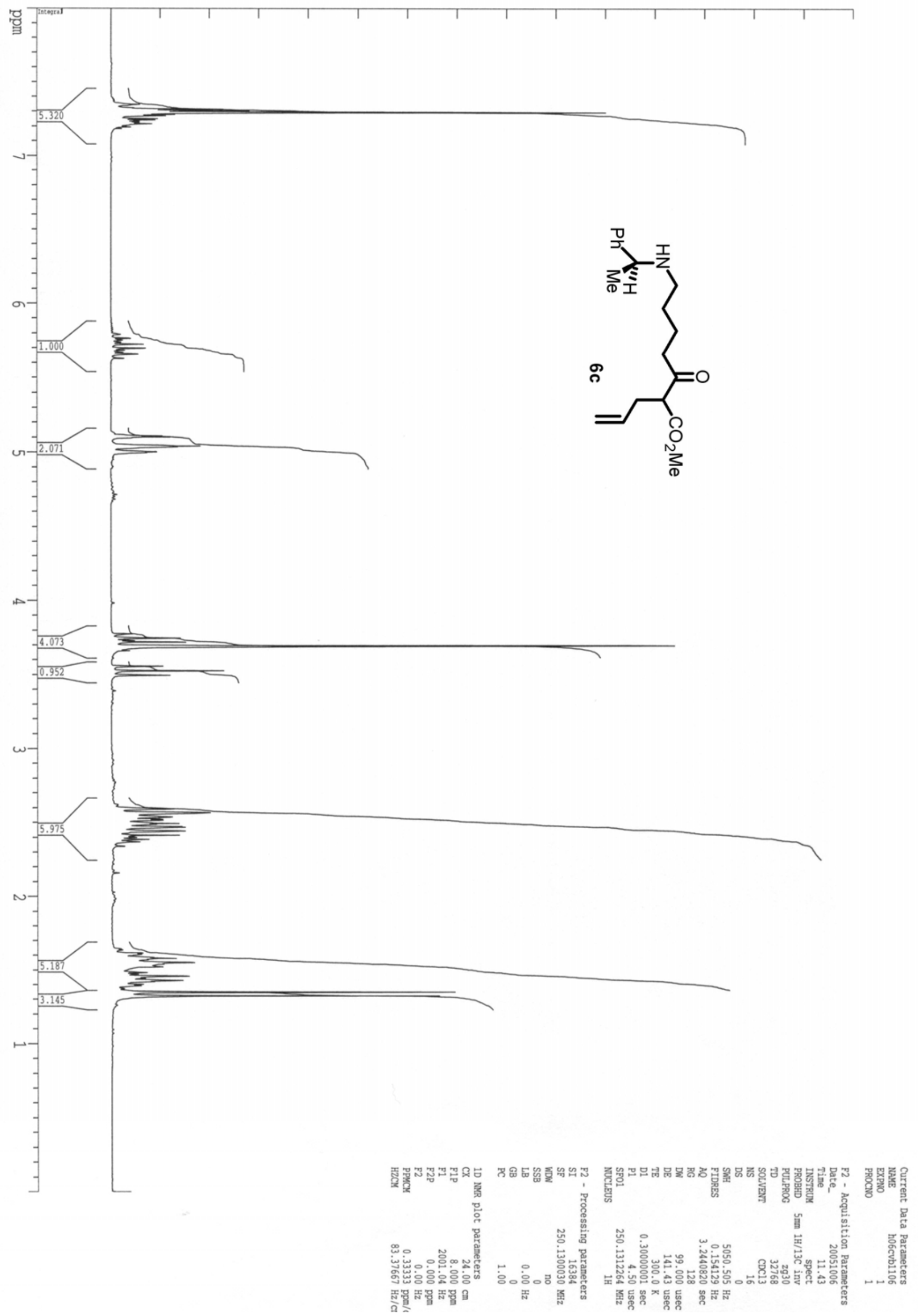



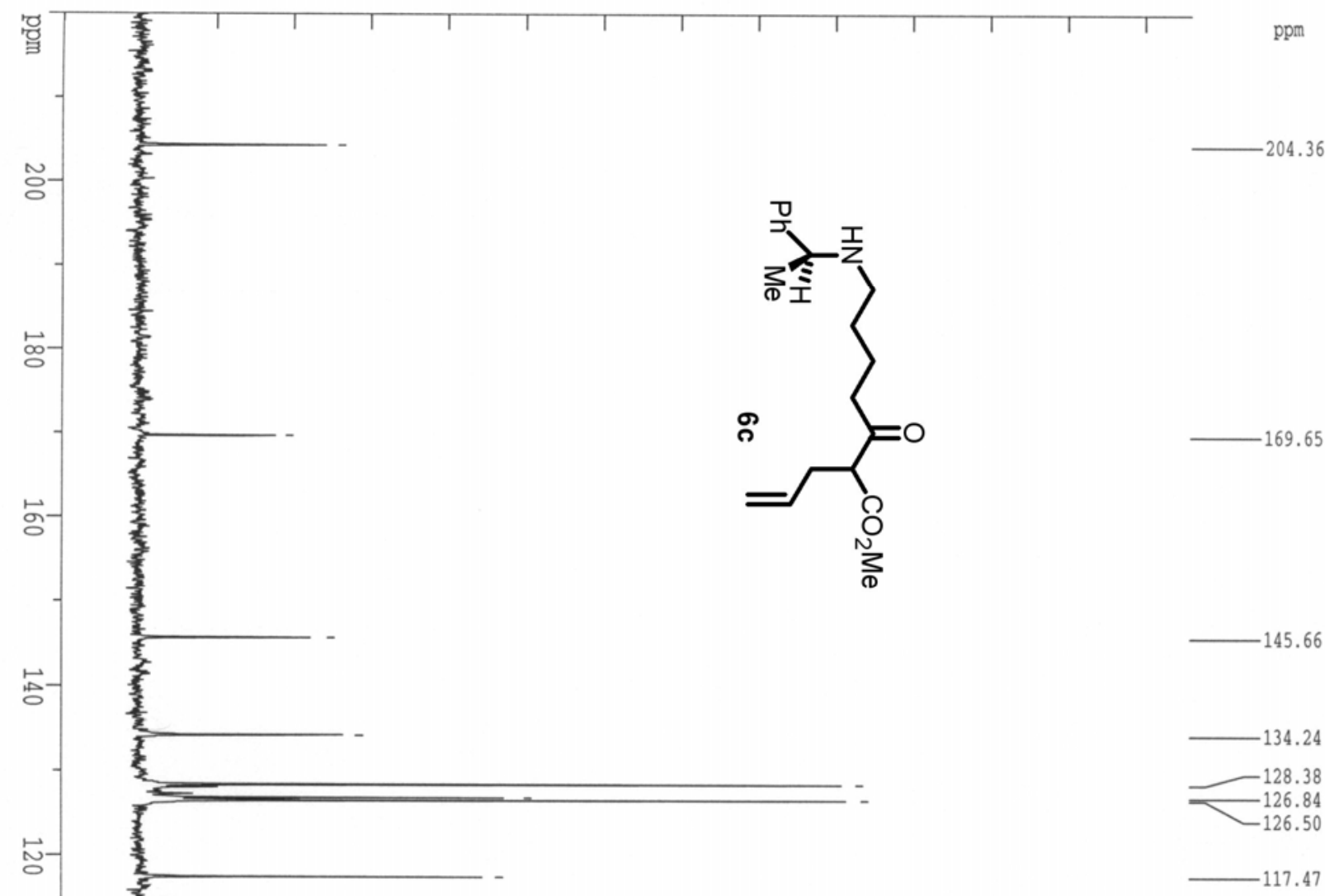

홍
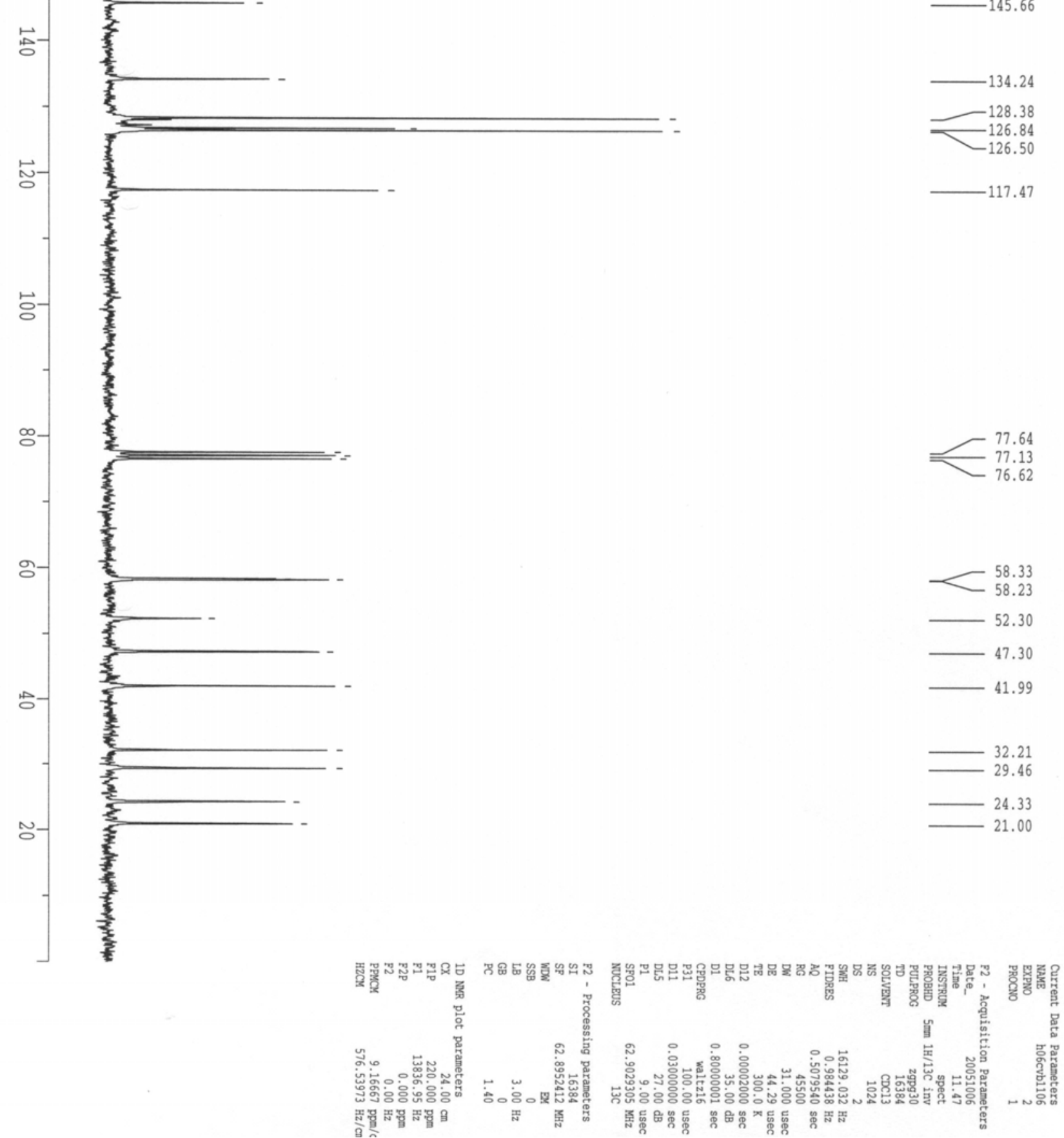


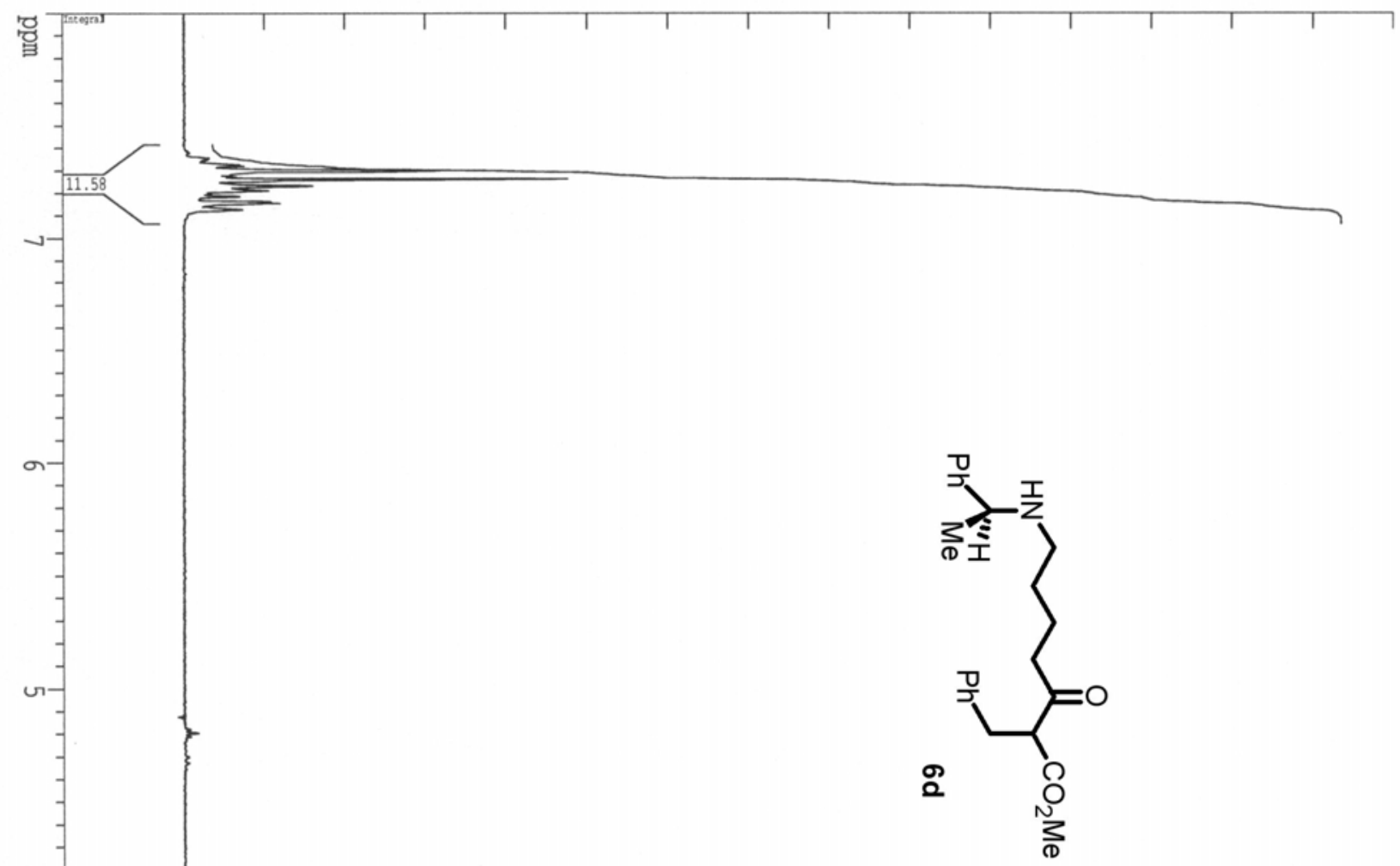

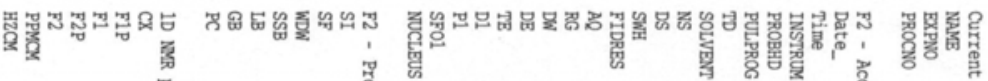

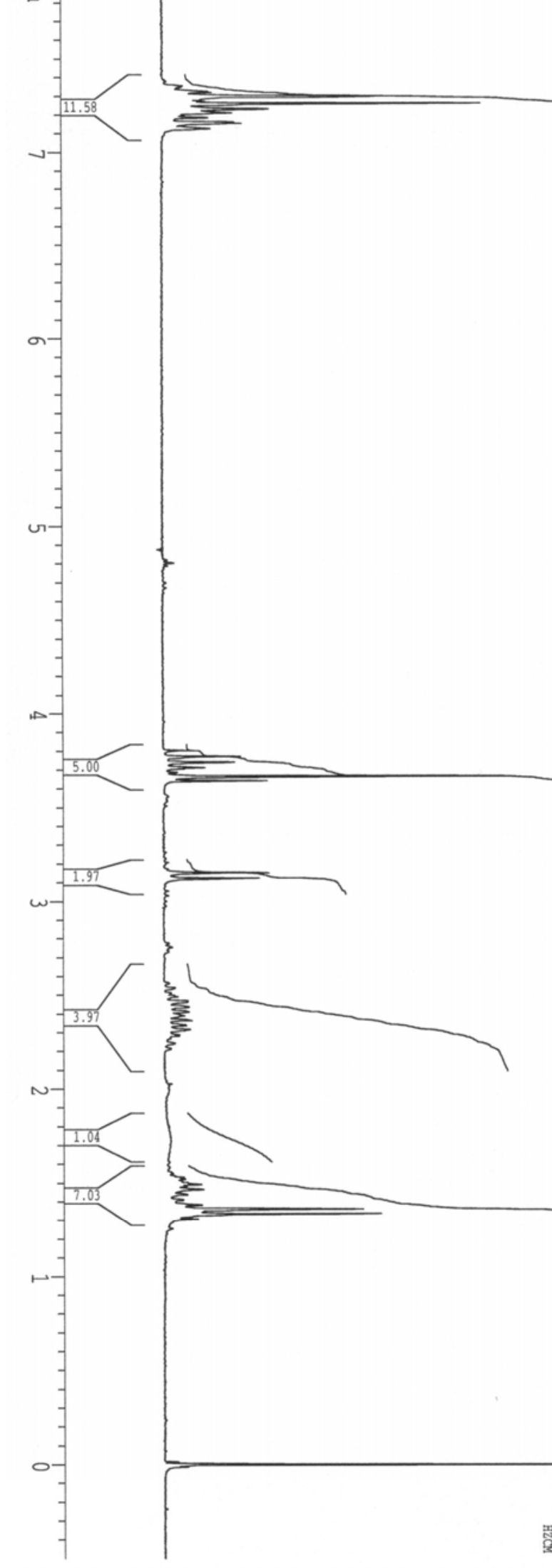



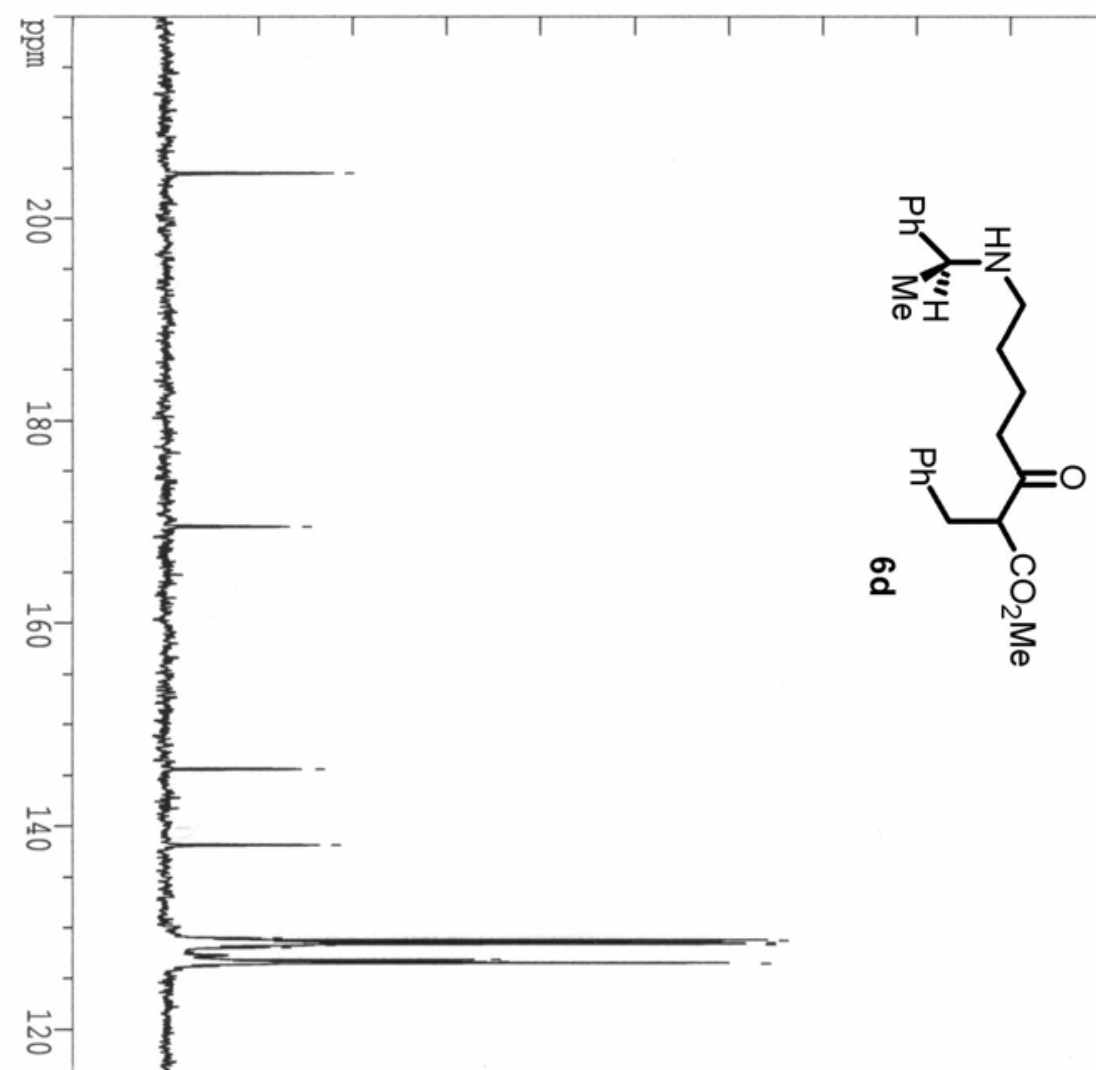

145.59 $-138.14$

$-128.77$ $-128.56$ 128.40 128.27 128.08 $-126.87$

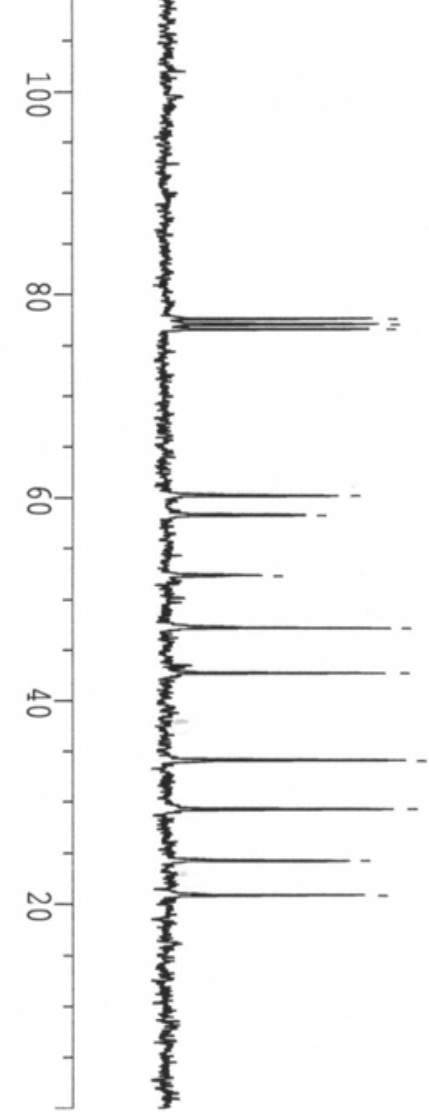

77.63 


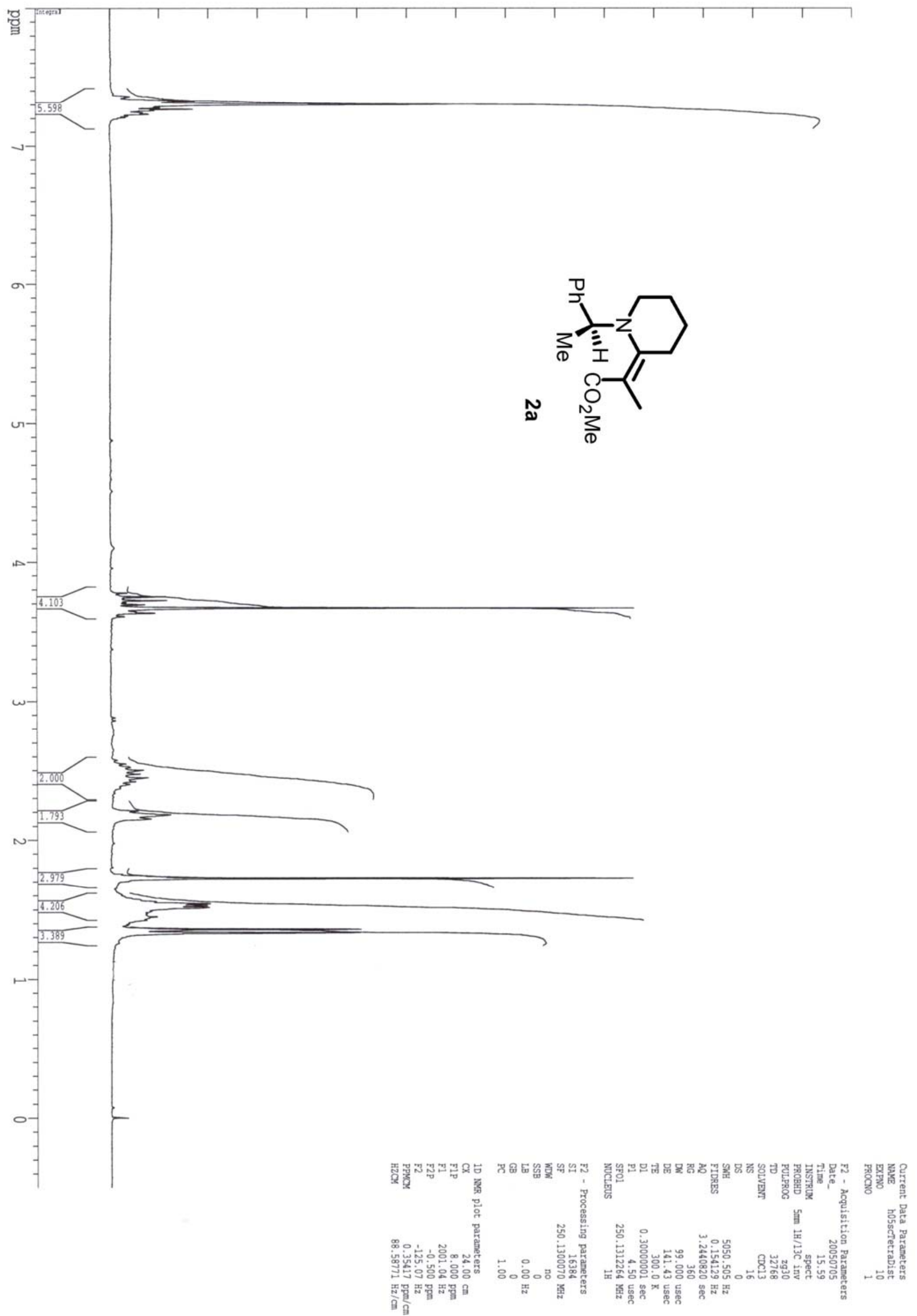




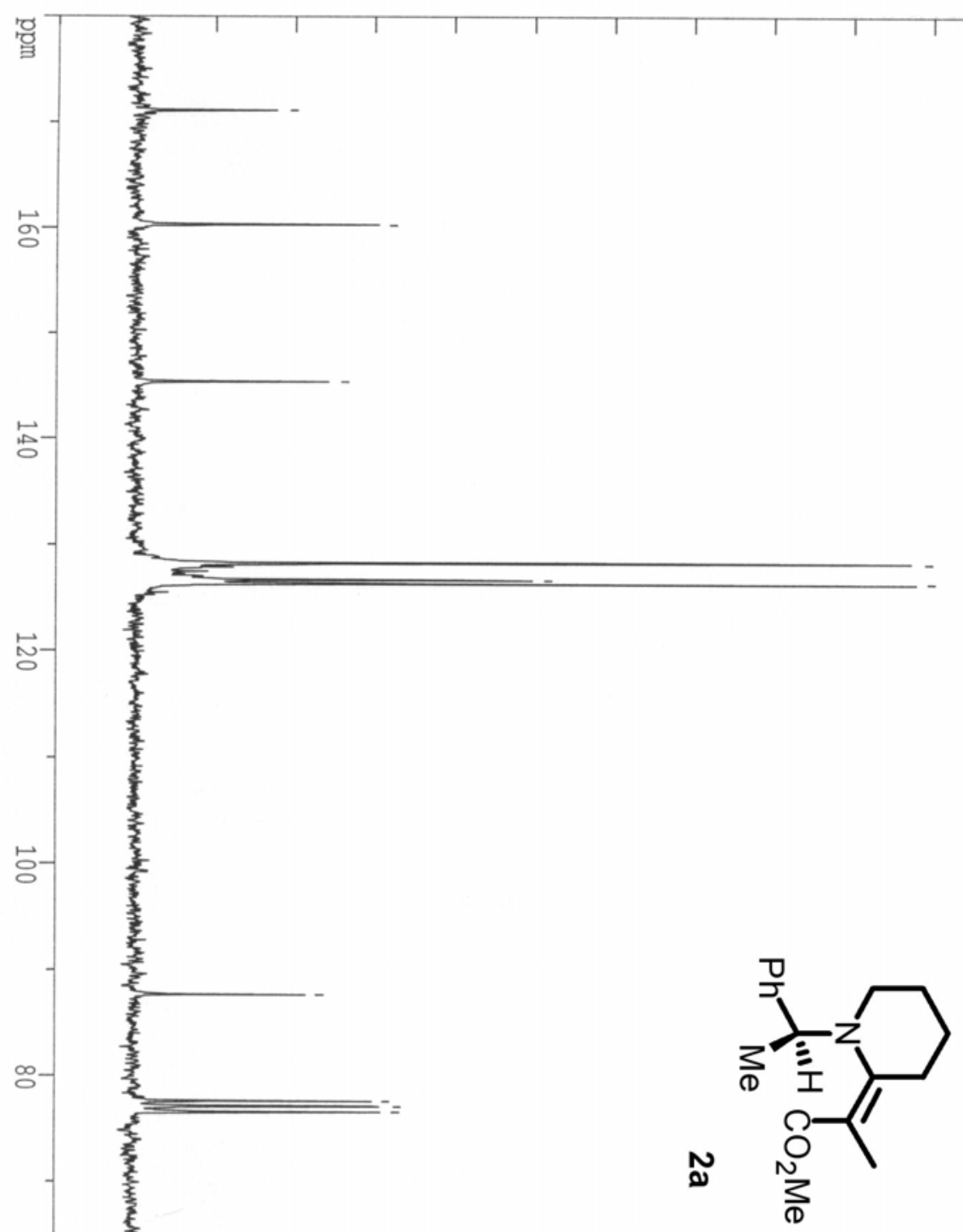

ppm
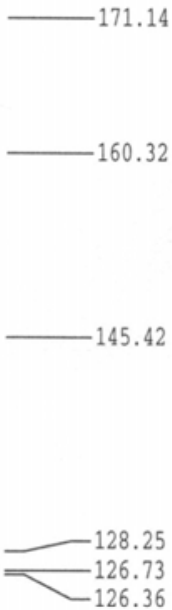

126.36

용

妾

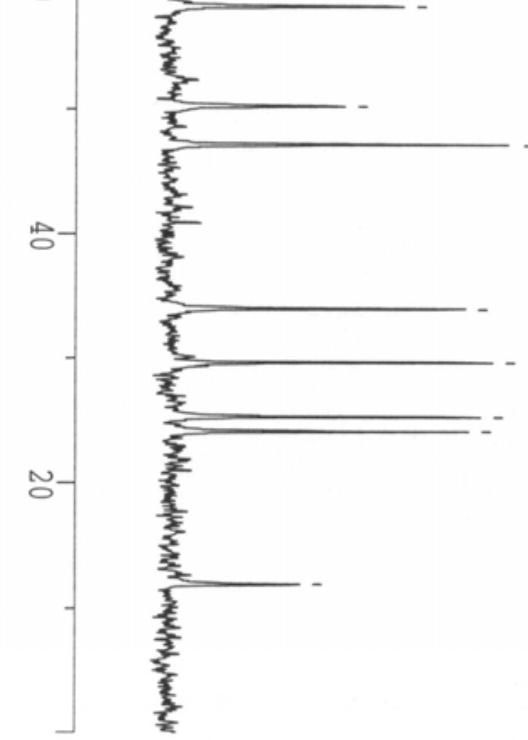

58.23

50.23

47.15

吕

33.95

29.66

25.27

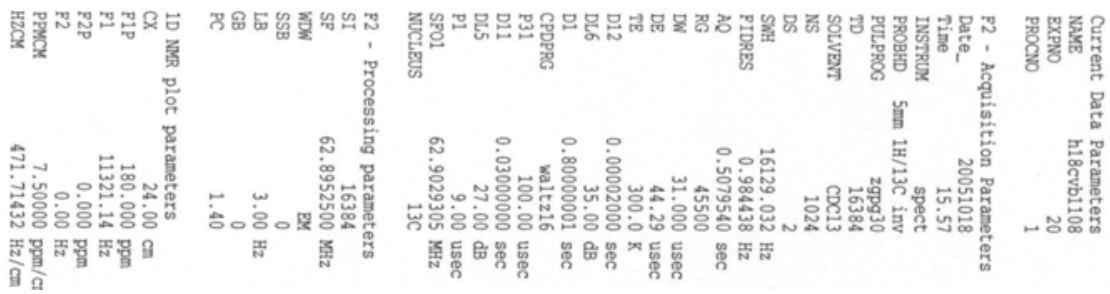




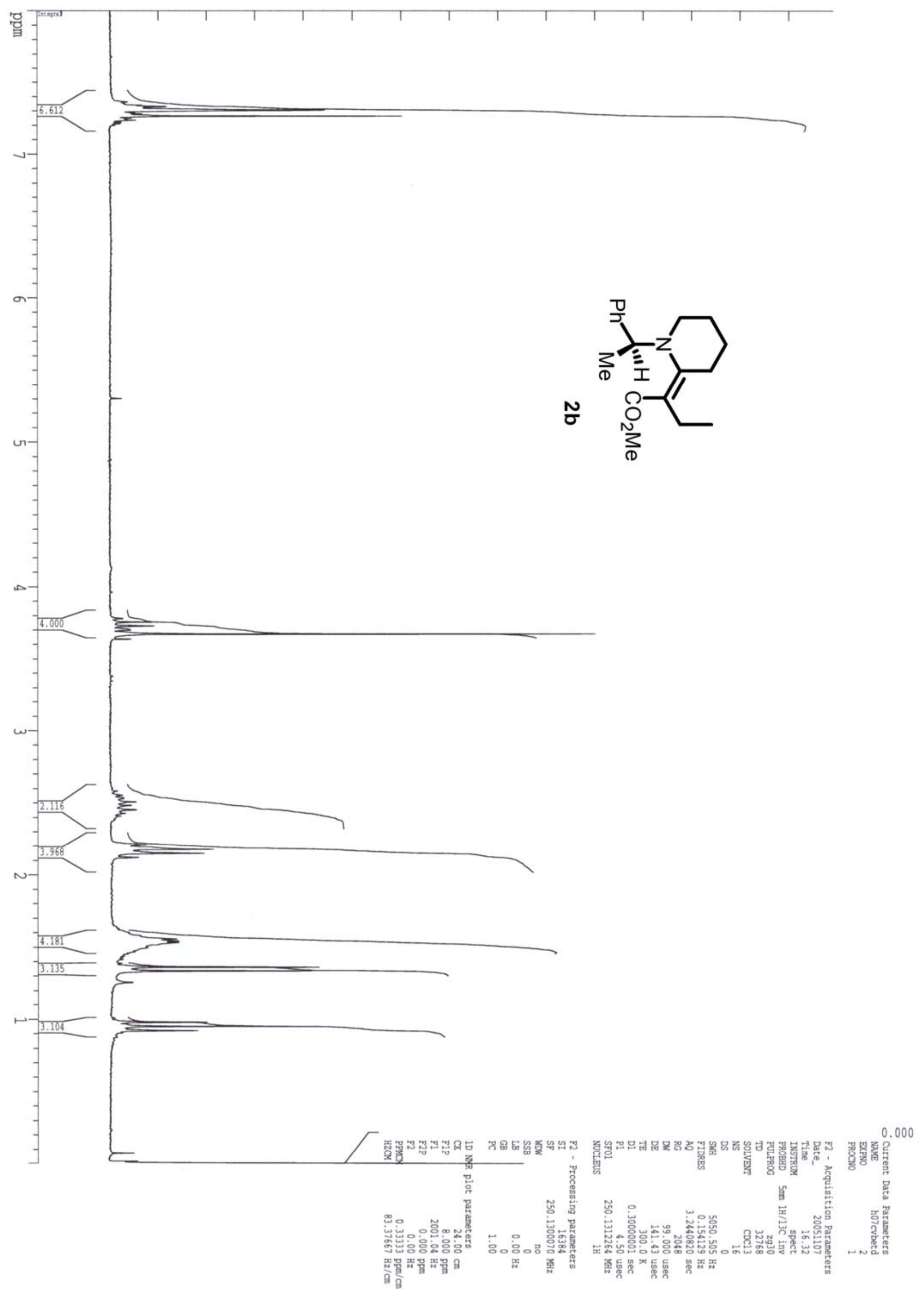



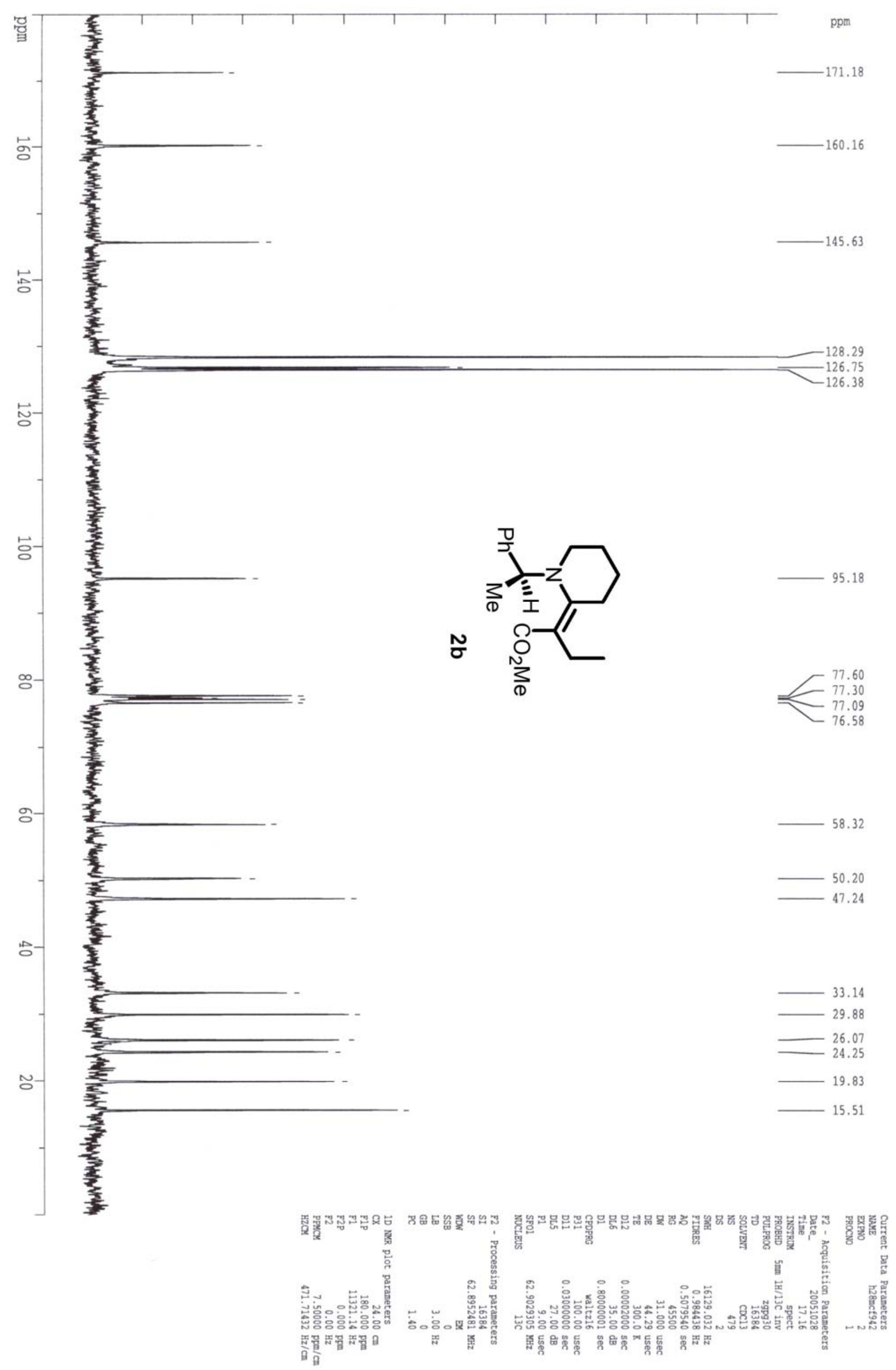


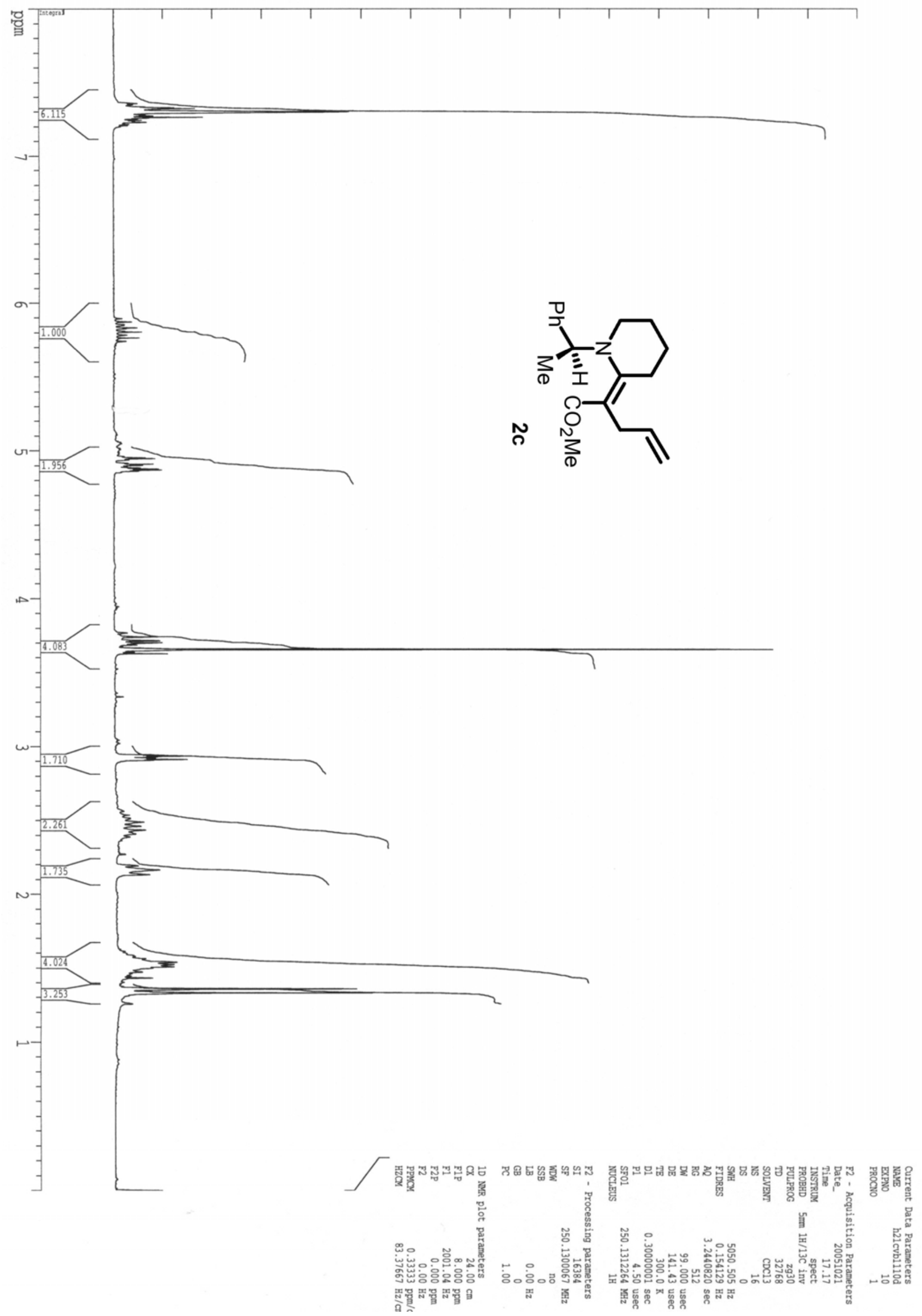



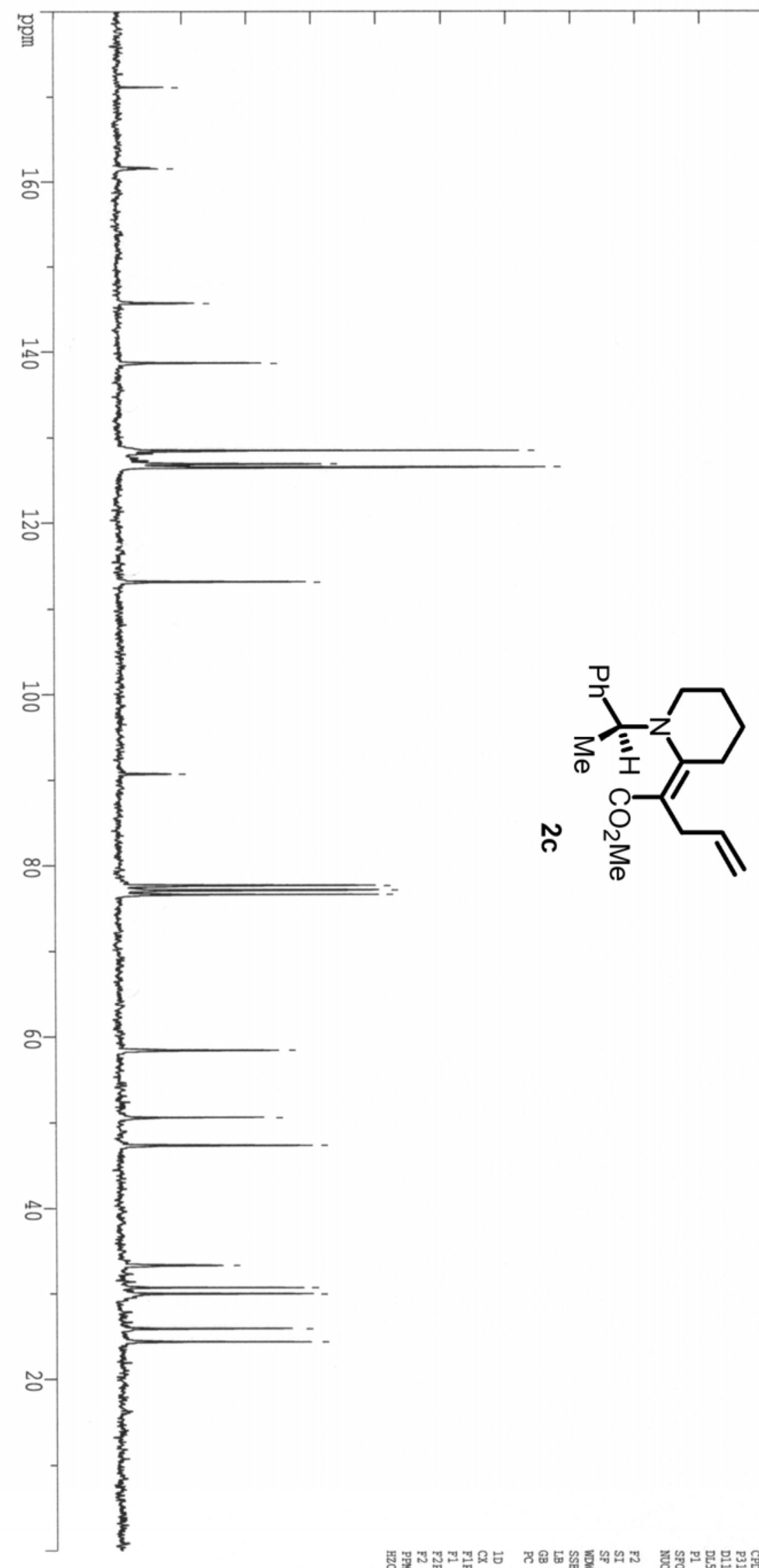

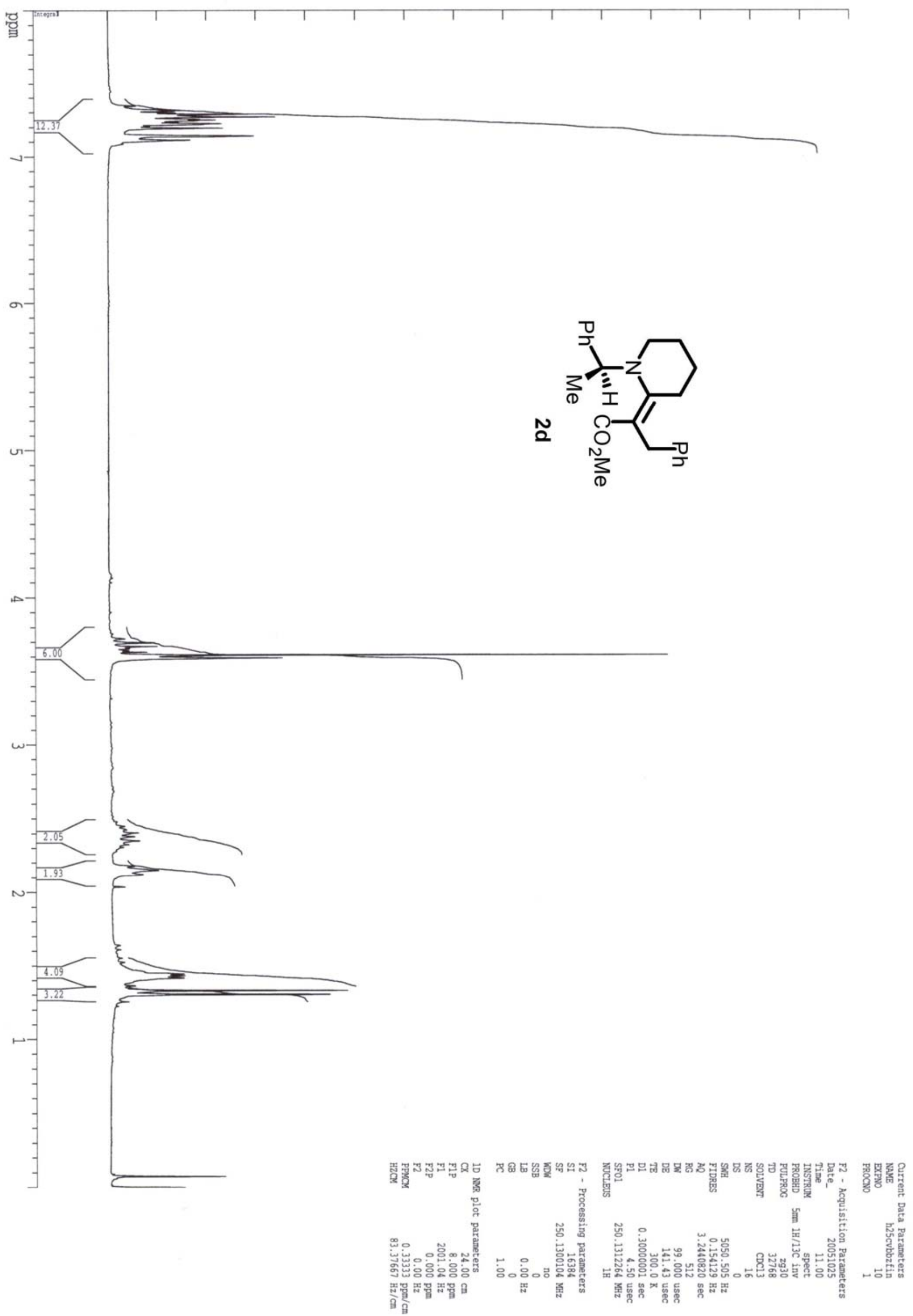

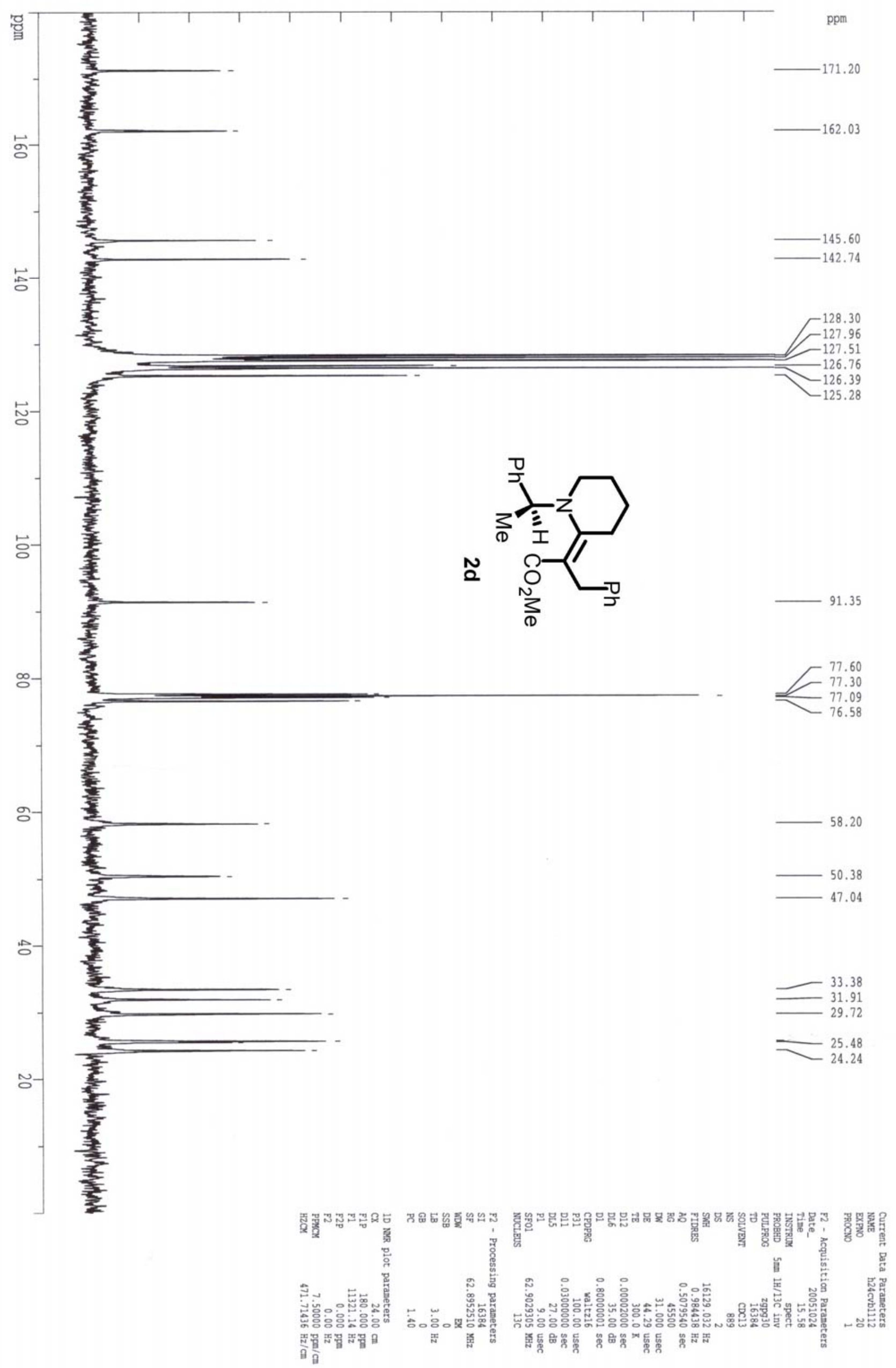


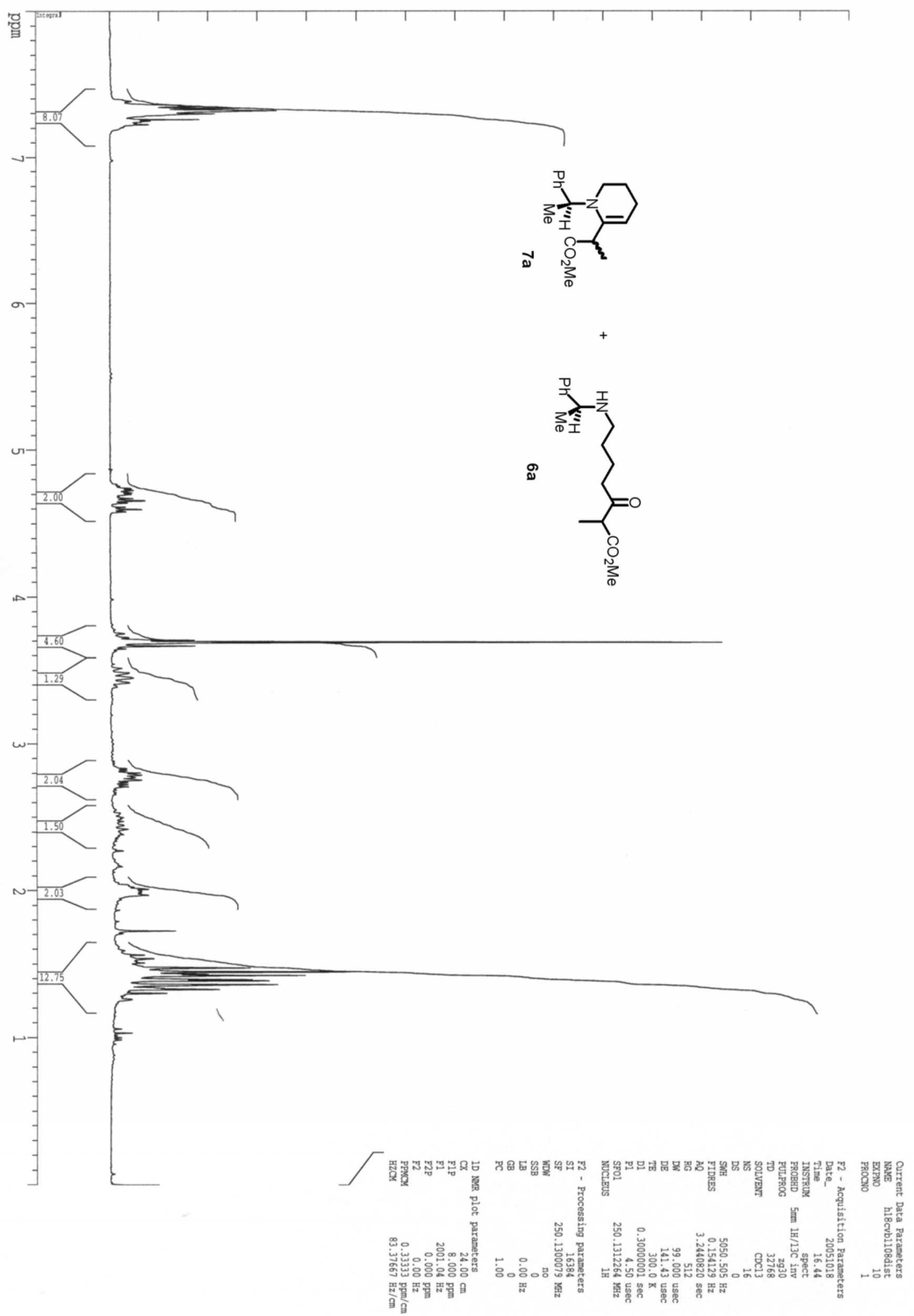




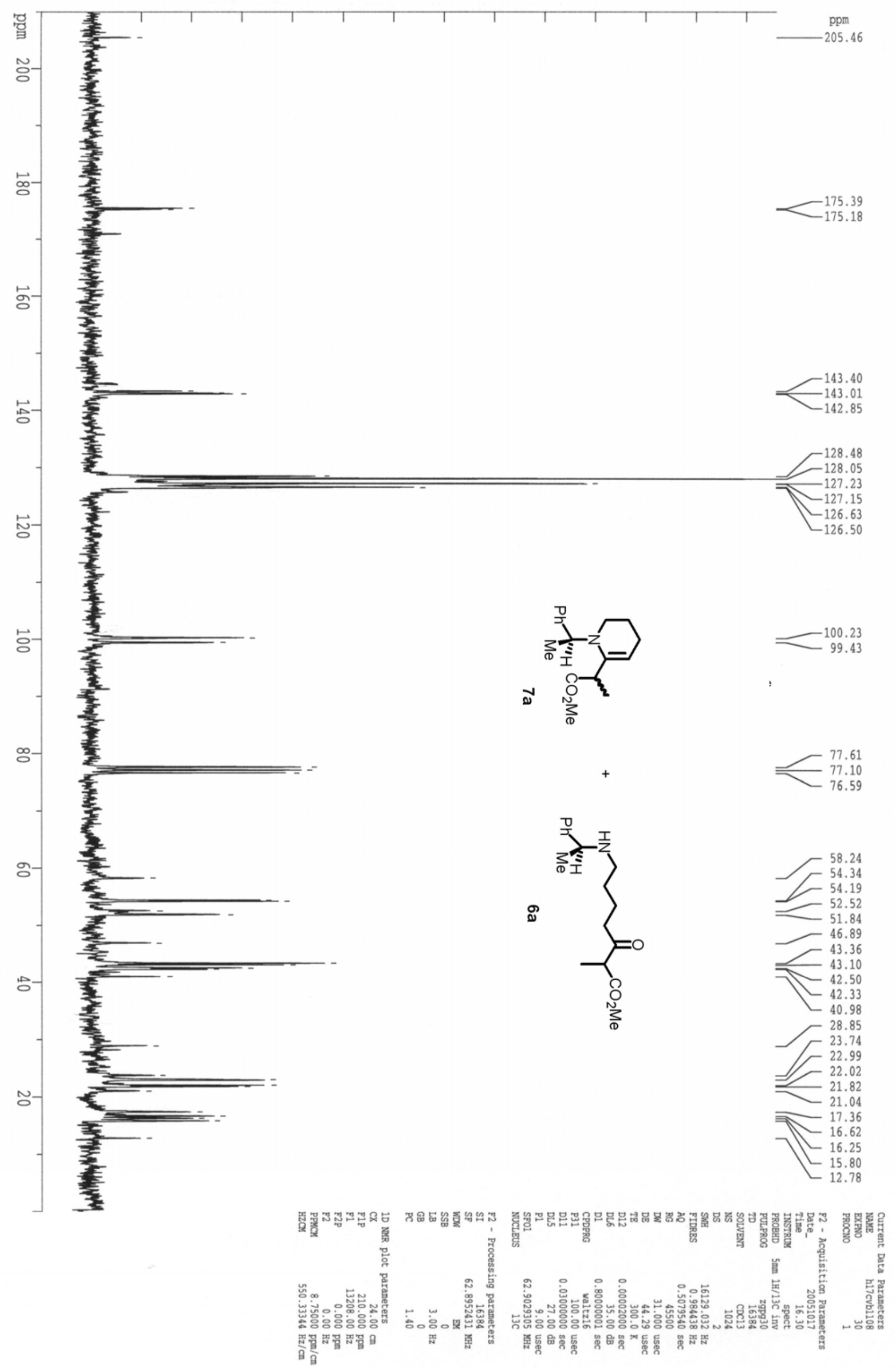

